\title{
Spatio-Temporal Variability of Droughts and Terrestrial Water Storage over Lake Chad Basin using Independent Component Analysis
}

\author{
Christopher E. Ndehedehe ${ }^{\mathrm{a}}$, Nathan O. Agutu ${ }^{\mathrm{a}, \mathrm{b}}$, Onuwa Okwuashi ${ }^{\mathrm{c}}$, Vagner G. Ferreira ${ }^{\mathrm{d}}$ \\ ${ }^{a}$ Western Australian Centre for Geodesy and The Institute for Geoscience Research Curtin University, Perth, \\ Australia. \\ ${ }^{b}$ Department of Geomatic Engineering and Geospatial Information systems JKUAT, Nairobi, Kenya. \\ ${ }^{c}$ Department of Geoinformatics and Surveying, University of Uyo, P.M.B. 1017, Uyo, Nigeria. \\ ${ }^{d}$ School of Earth Sciences and Engineering, Hohai University, Nanjing, China
}

\section{Abstract}

Lake Chad has recently been perceived to be completely desiccated and almost extinct due to insufficient published ground observations. Given the high spatial variability of rainfall in the region, and the fact that extreme climatic conditions (for example, droughts) could be intensifying in the Lake Chad basin (LCB) due to human activities, a spatio-temporal approach to drought analysis becomes essential. This study employed independent component analysis (ICA), a fourth-order cumulant statistics, to decompose standardised precipitation index (SPI), standardised soil moisture index (SSI), and terrestrial water storage (TWS) derived from Gravity Recovery and Climate Experiment (GRACE) into spatial and temporal patterns over the LCB. In addition, this study uses satellite altimetry data to estimate variations in the Lake Chad water levels, and further employs relevant climate teleconnection indices (El-Niño Southern Oscillation-ENSO, Atlantic Multi-decadal Oscillation-AMO, and Atlantic Meridional Mode-AMM) to examine their links to the observed drought temporal patterns over the basin. From the spatio-temporal drought analysis, temporal evolutions of SPI at 12 month aggregation show relatively wet conditions in the last two decades (although with marked alterations) with the $2012-2014$ period being the wettest. In addition to the improved rainfall conditions during this period, there was a statistically significant increase of $0.04 \mathrm{~m} / \mathrm{yr}$ in altimetry water levels observed over Lake Chad between 2008 and 2014, which confirms a shift in the hydrological conditions of the basin. Observed trend in TWS changes during the $2002-2014$ period shows a statistically insignificant increase of $3.0 \mathrm{~mm} / \mathrm{yr}$ at the center of the basin, coinciding with soil moisture deficit indicated by the temporal evolutions of SSI at all monthly accumulations during the 2002 - 2003 and $2009-2012$ periods. Further, SPI at 3 and 6 month scales indicated fluctuating drought conditions at the extreme south of the basin, coinciding with a statistically insignificant decline in TWS of about $4.5 \mathrm{~mm} / \mathrm{yr}$ at 
the southern catchment of the basin. Finally, correlation analyses indicate that ENSO, AMO, and AMM are associated with extreme rainfall conditions in the basin, with AMO showing the strongest association (statistically significant correlation of 0.55) with SPI 12 month aggregation. Therefore, this study provides a framework that will support drought monitoring in the LCB.

Keywords: TWS, Soil moisture, ICA, SPI, Drought, Rainfall

\section{Introduction}

Lake Chad Basin (LCB), the world's largest interior drainage basin, covers an approximate area of 2,500,000 $\mathrm{km}^{2}$ and supports an estimated 37 million people who depend on its water resources for agriculture, fishing, and other domestic applications (e.g., Coe and Birkett, 2004; Leblanc et al., 2003). The basin is geographically bounded by latitudes $6^{\circ} \mathrm{N}$ and $24^{\circ} \mathrm{N}$ and longitudes $7^{\circ} \mathrm{W}$ and $24^{\circ} \mathrm{E}$ (Fig. 1) and is occupied by Lake Chad at the centre, a prominent freshwater body, which largely forms the live wire of the basin's hydrology. The historic and dramatic decline in the spatial extent of the Lake from $24,000 \mathrm{~km}^{2}$ in the 1950 's to segmented open water pool of approximately $1700 \mathrm{~km}^{2}$ (i.e., about $90 \%$ decline) in recent times, has been reported (see, e.g., Wald, 1990; Birkett, 2000; Coe and Foley, 2001; Leblanc et al., 2003; Lemoalle et al., 2012). Lake Chad receives its water supply primarily from the Chari-Logone river, which provides approximately $95 \%$ of the total inflows into the southern pool, and also the Komadugu-Yobe River (see Fig. 2), which provides less than $2.5 \%$ of water that flows into the northern pool of the Lake (Birkett, 2000; Coe and Birkett, 2004). In relation to other Lakes in Africa, recent illustration of Lake Chad presupposes a completely desiccated and almost extinct Lake (e.g., Moore and Williams, 2014; Coe and Foley, 2001; Birkett, 2000). This perception may be partly associated with lack of documented analyses of satellite-based observations (Lemoalle et al., 2012). Consequently, the drought narrative of the Lake and the entire LCB has been a subject of much less scientific discussion.

A number of studies on Lake Chad's hydrology and the corresponding basin have been carried out. For example, Coe and Birkett (2004) used satellite radar altimetric measurements of water height to estimate river discharge at the Chari/Ouham confluence while Lemoalle et al. (2012) used a hydrological model to reconstruct the past water levels of the Lake and inundated areas from 1973 to 2011 in order to compensate for the lack of hydrological data. Birkett (2000) and Coe and Foley (2001) had earlier reported the combined effects of regional precipitation patterns and the impact of human activities on the desiccation of the Lake while Okonkwo 
et al. (2014) examined the relationship of El-Niño Southern Oscillation (ENSO) with rainfall, river discharge at Chari river, and Lake Chad water level at Kalomand Kindjeria. Leblanc et al. (2003) used Advanced Very High Resolution Radiometer (AVHRR) and Meteosat data in a Geographic Information System (GIS) framework to map the fluctuations of the spatial extent of Lake Chad. But recently, Lopez et al. (2016) studied the quaternary phreatic aquifer of the basin, indicating that there is an association between piezometric levels and sedimentary thickness.

However, from the studies highlighted so far, we find a relatively strong research lacuna in the knowledge of water availability, drought patterns, and spatio-temporal variability of water storage over the LCB. Apart from the effort of Okonkwo et al. (2013), which provided a location-specific information regarding the probability distribution of rainfall and drought in the LCB during the 2002-2011 period, drought studies in the LCB are generally lacking and largely undocumented. Also, with increased human activities (e.g., irrigation schemes) in LCB (e.g., Lemoalle et al., 2012; Coe and Foley, 2001), especially within the precinct of the Lake, one may assume that the water resources of the basin could be more vulnerable, given the significant global drying trends observed in water availability and hydrological regimes in the Sahel region of West Africa (Greve et al., 2014). Furthermore, in the wake of global climate change and perturbations of ocean warming, it is likely that the limited alimentation occasioned by lack of or deficit in precipitation and human activities in the basin might get worse in the future. This may have significant impact on the local economy and the freshwater tributaries (that is, Chari and Logone rivers) that nourishes Lake Chad.

Furthermore, despite the recognised recovery of rainfall in some parts of the Sahel region (see, Nicholson, 2013, and the references therein), the impact of this recovery on the hydrology of Lake Chad and TWS changes over the entire basin are still rather unclear, largely unknown, and undocumented. For instance, in addition to the inconsistent trends between increased rainfall and lake level, Okonkwo et al. (2014) showed that the variability in ENSO could explain only $31 \%$ and $13 \%$ of variations in Lake Chad water level at Kindjeria and precipitation in the northern LCB, respectively. Notably, the LCB has been ravaged by frequent droughts leading to limited freshwater availability. The reduced alimentation of the basin in terms of freshwater shortage can be seen in the yearly water balance as reported by Odada et al. (2005). They reported that there was an inflow and outflow of $24.68 \mathrm{~km}^{3} / \mathrm{yr}$ and $24.5 \mathrm{~km}^{3} / \mathrm{yr}$, respectively, with evapotranspiration being a major component of the outflow (approximately $23.1 \mathrm{~km}^{3} / \mathrm{yr}$ ) in the basin between 1971 and 1990. Added to this is the drought narrative for the region, 
which may be highly generalised (that is, in terms of its spatial variability, characteristics, etc.) due to lack of an optimised framework to determine its space-time occurrence. Considering the high spatial variability of rainfall in the region, and the fact that extreme climatic conditions could be intensifying in the basin possibly due to anthropogenic factors (for example, water abstractions for irrigation), a spatio-temporal approach to drought analysis becomes vital.

Numerous studies, mostly in the mainstream of satellite hydrology, have shown how multisatellite data from altimetry, gravimetry, and optical remote sensing platforms can be used to estimate terrestrial water storage $(\mathrm{TWS})^{1}$ variations in drainage basins and poorly gauged regions, in addition to estimating water volume variations from surface waters such as lakes and reservoirs (see, e.g., Tourian et al., 2015; Baup et al., 2014; Duan and Bastiaanssen, 2013a). In particular, the launch of Gravity Recovery and Climate Experiment (GRACE) satellite mission (Tapley et al., 2004) has enabled hydrologists to validate water storage outputs from hydrological models and also to fully utilize GRACE observations for the inter-annual variations of TWS and water balance studies (see, Wouters et al., 2014, and the references therein). While few hydrological studies that utilized GRACE data in West Africa (see, e.g., Ndehedehe et al., 2016a; Grippa et al., 2011; Hinderer et al., 2009) have been reported, some drought studies and extreme rainfall conditions have also been documented in other sub-regions of West Africa (see, e.g., Ali and Lebel, 2009; Ndehedehe et al., 2016b; Masih et al., 2014; Bader and Latif, 2011; Nicholson et al., 2000; Nicholson, 2013, and the references therein). Despite the progress made so far in the use of GRACE data in hydrological studies, for instance, applications in drought and flood estimation (e.g., Reager et al., 2014; Yirdaw et al., 2008), the potential of GRACE data in monitoring the space-time development of TWS changes and droughts in the LCB are yet to be fully explored.

In this study, we capitalize on GRACE observations to estimate the TWS over the LCB, in addition to satellite altimetry-derived water levels and other hydrological variables such as rainfall, and soil moisture to monitor water storage changes and the spatio-temporal characteristics of droughts. Contrary to previous studies that have analysed spatio-temporal drought events in other regions of the world (see, e.g., Bazrafshan et al., 2014; Santos et al., 2010; Bonaccorso et al., 2003) using principal component analysis (e.g., Jolliffe, 2002), we employ independent component analysis (ICA, see, e.g., Cardoso, 1999; Common, 1994; Cardoso and Souloumiac, 1993), a higher order statistical method to localize drought patterns and time-

\footnotetext{
${ }^{1}$ The sum total of surface waters (i.e., rivers, lakes, and wetlands), soil moisture, canopy, and groundwater.
} 
variable hydrological signals (i.e., TWS). Unlike in the Volta basin where the influence of low frequency climate oscillations on hydrological drought was reported by Ndehedehe et al. (2016b), here, the Lake Chad basin (a semi-arid Sahelian environment) is adopted as a tentative test bed, primarily to demonstrate the use of a fourth-order cumulant statistics such as the ICA to analyze spatio-temporal evolutions of drought indices at different time scales (3, 6, and 12 months aggregation), and to examine the relationship of other climate modes (i.e., ENSO, AMO, and AMM), which were not considered with drought temporal evolutions in the Volta basin. Such analysis is essential not only in understanding drought variability, but also the causes of rainfall variability, which though unclear has been somewhat associated with sea surface temperature anomalies of the nearby Oceans (e.g., Bader and Latif, 2011). For the drought analysis, we used the recently introduced standardised non-parametric univariate and multivariate drought indices (see, Hao and AghaKouchak, 2013, 2014; Farahmand and AghaKouchak, 2015) for the characterisation of different droughts (e.g., meteorological, agricultural, and hydrological) over LCB. The ICA technique was employed to statistically decompose SPI and standardised soil moisture index (SSI) values into spatial and temporal patterns while the multivariate standardised index (MSDI), was used to evaluate the effectiveness of two climate variables (rainfall and soil moisture) in capturing drought properties such as frequency, persistence, and termination. This study specifically aims at (i) localising and characterising spatio-temporal evolutions of drought patterns over the LCB and (ii) identifying spatial variability of TWS changes and the estimation of trends in lake height variations over the LCB.

While we provide background information on the spatio-temporal variability of drought patterns in Section 2, further details on the method and the results of the study are presented in Sections 3 and 4, respectively.

\section{Spatio-temporal Variability of Drought}

The lack of in-situ measurements to assist in hydrological monitoring limits the prospects of a robust, large scale monitoring of major hydrological variables (i.e., rainfall, water levels, groundwater, and river discharge) in the LCB. Standard routine measurements of these hydrological quantities are lacking due to limited gauge stations and deterioration of existing hydrological facilities. Although local measurements from dedicated regional networks such as the African Monsoon Multidisciplinary Analysis-Couplage de l'Atmosphère Tropicale et du Cycle Hydrologique (AMMA-CATCH, Lebel et al., 2009) hydro-meteorological observing sys- 


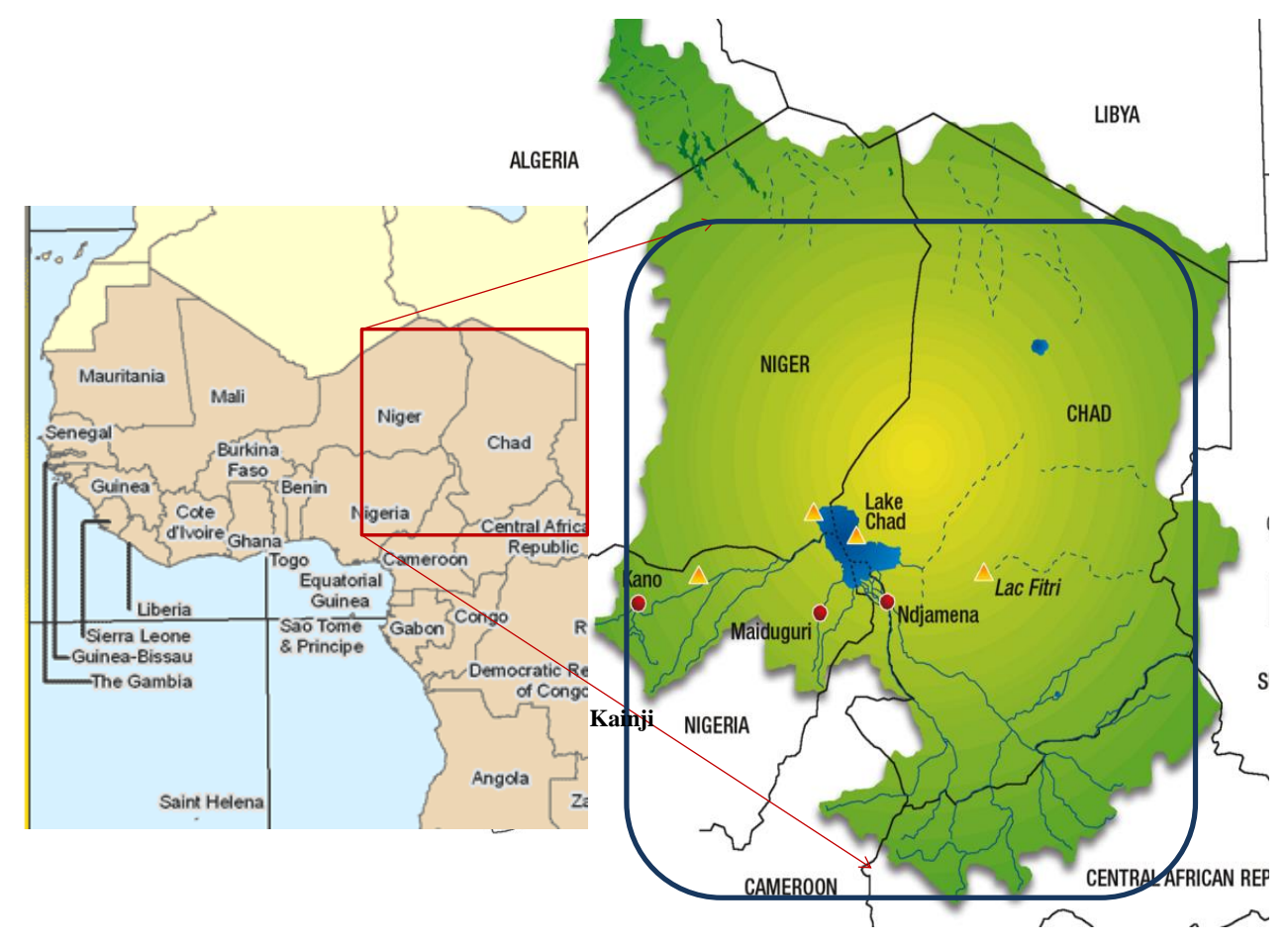

Figure 1: Study area showing Lake Chad, the riparian countries that constitute the Lake Chad basin, and important river networks (blue line) within the basin. Our analysis focuses on the conventional basin area (a subset of the blue polygon), which includes mostly southern and north eastern sections of Niger, Chad, northeastern Nigeria, northern Cameroon, and most parts of Central African Republic. Maps are adapted from www.worldmap.org and http://assets.panda.org/img/original/chadmap.gif. The LCB lies at the south western crossroads of the Sahel and forest savanna, a transition zone between the Sahara Desert and the tropical savanna of West Africa (Okonkwo et al., 2013).

tem have been used in some studies (e.g., Gosset et al., 2013), the AMMA-CATCH networks are highly insufficient for a regional study as they are only available in few countries (i.e., Niger, Mali, and Benin). Further, while most available data cannot be accessed by the public and relevant research institutions as a result of government policies and bureaucracies, political instability in the sub-regions complicates efforts to acquire such data. In addition, incomplete data records and gaps in available data tend to affect proper assessment and monitoring of hydrological conditions in the region.

However, with the plethora of available climate data either in the form of satellite observations or model-generated products, monitoring hydro-climatic conditions is somewhat not difficult. The critical issues have often revolved around the understanding and localisation of these multiple and growing climate signals. For instance, the use of mean standardised precipitation index (SPI, McKee et al., 1993) time series in estimating drought conditions over the Sahel has not been very effective. This is because of the influence of strong spatial variability 


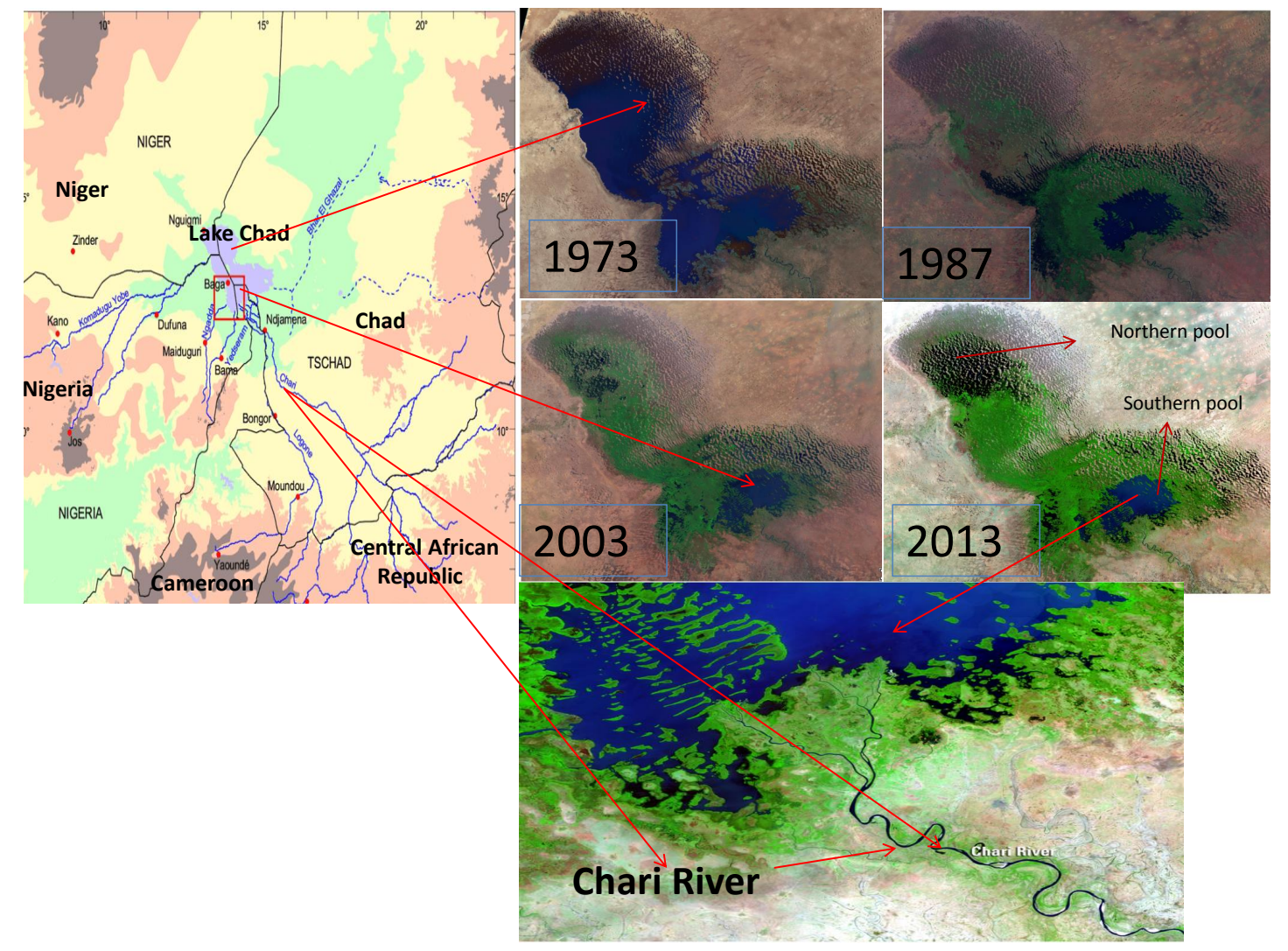

Figure 2: The spatial and temporal changes in Lake Chad surface area as shown by Landsat imageries for 1973, 1987, 2003, and 2013. The Chari river, which provides about $95 \%$ of the inflow to the Lake is indicated. The blue lines on the map (left) show the river networks within the basin most of which constitute the Chari river system. The present Lake Chad show two segmented pools with the northern pool completely dried up during drought periods (right). Maps and imageries are adapted from (i) wwwstud.informatik.uni-frankfurt.de/sfb268/d6/pics/misc/franke2000gr-abb1-gross.gif and (ii) United States geological surveys (http://earthshots.usgs.gov/earthshots/Lake-Chad-West-Africa).

of rainfall at annual scale and the mean inter-annual climatological gradients across the region (Ali and Lebel, 2009). Schewe et al. (2013) described the signal problem more succinctly, indicating that at regional scales, the projections of climate models for instance, in terms of precipitation patterns and magnitudes, are inconsistent when compared to global average changes. This unavoidably leads to uncertainties in the attempt to understand the effect of climate change on water resources at regional scales. In West Africa, Ali and Lebel (2009) reported that despite the significantly dry season of 2006, working with a rainfall product with spatial resolution of $0.5^{\circ} \times 0.5^{\circ}$ resulted in only $28 \%$ of the area being significantly dried while $15 \%$ of the Sahel region was significantly wet. They also observed that SPI on a $1^{\circ} \mathrm{x} 1^{\circ}$ grid in the Sahel was not representative of the whole region. Irrespective of the spatial resolution of the data and differences in climatic zones, drought analysis from a spatio-temporal point of 
view can improve our understanding of drought occurrence. One approach to spatio-temporal drought analysis would be the use of a component extraction technique, in particular, principal component analysis (PCA, Jolliffe, 2002). For example, Bazrafshan et al. (2014) in a recent study reported on the multivariate approach, which uses the PCA of the SPI time series in capturing the temporal variability of drought patterns at different time scales (i.e., 3, 6, and 12 month scale) while Bonaccorso et al. (2003) studied long-term drought variability in Sicily during 1926-1996 period using the PCA technique. Further, using PCA and K-means clustering, Santos et al. (2010) was able to show that the south of Portugal had more frequent cycles of dry events (every 3.6 years) than the northern part where severe to extreme droughts occurred approximately every 13.4 years. Following the strong spatial variability of rainfall in the Sahel region where LCB is located, our approach uses a regionalisation process where the decomposed SPI time series from PCA are rotated towards statistical independence, a process referred to as independent component analysis (e.g., Aires et al., 2002; Cardoso, 1999; Cardoso and Souloumiac, 1993). Our approach differs from the aforementioned studies in that the derived SPI time series, which are based on a non-parametric approach derived from the empirical probability method (see Farahmand and AghaKouchak, 2015; Hao and AghaKouchak, 2014) are decomposed through a classical rotation of the PCA modes. This is done in a way to enable the localisation and extraction of physically meaningful drought signals that are statistically significant. The use of a regionalization method such as the ICA enables the localization of SPI and standardised soil moisture index (SSI) signals in terms of its spatial variability and temporal evolutions in the basin. This approach is useful in understanding the space-time evolution of extreme rainfall and soil moisture conditions in the basin. For an endorheic basin such as the LCB, which lacks a suitable framework to monitor space-time occurrence of drought, this approach to drought monitoring, when integrated with the analysis of changes in TWS and altimetry derived water levels of Lake Chad, largely supports the assessment of available water resources. We provide more details on the ICA technique in Section 3 .

Moreover, in this study, we hypothesized that following the dramatic decline and desiccation of Lake Chad surface area due to strong precipitation deficit of the 1980's (see cumulative rainfall anomalies, Fig. 3), meteorological drought propagates into both agricultural and hydrological droughts with strong impact on the catchment stores (i.e., lakes, rivers, soil water, and aquifers). Several drought studies have associated hydrological drought with precipitation deficit on a longer time scale such as 6, 12, and 24 months (see, e.g., Li and Rodell, 2015; 

hydrological).
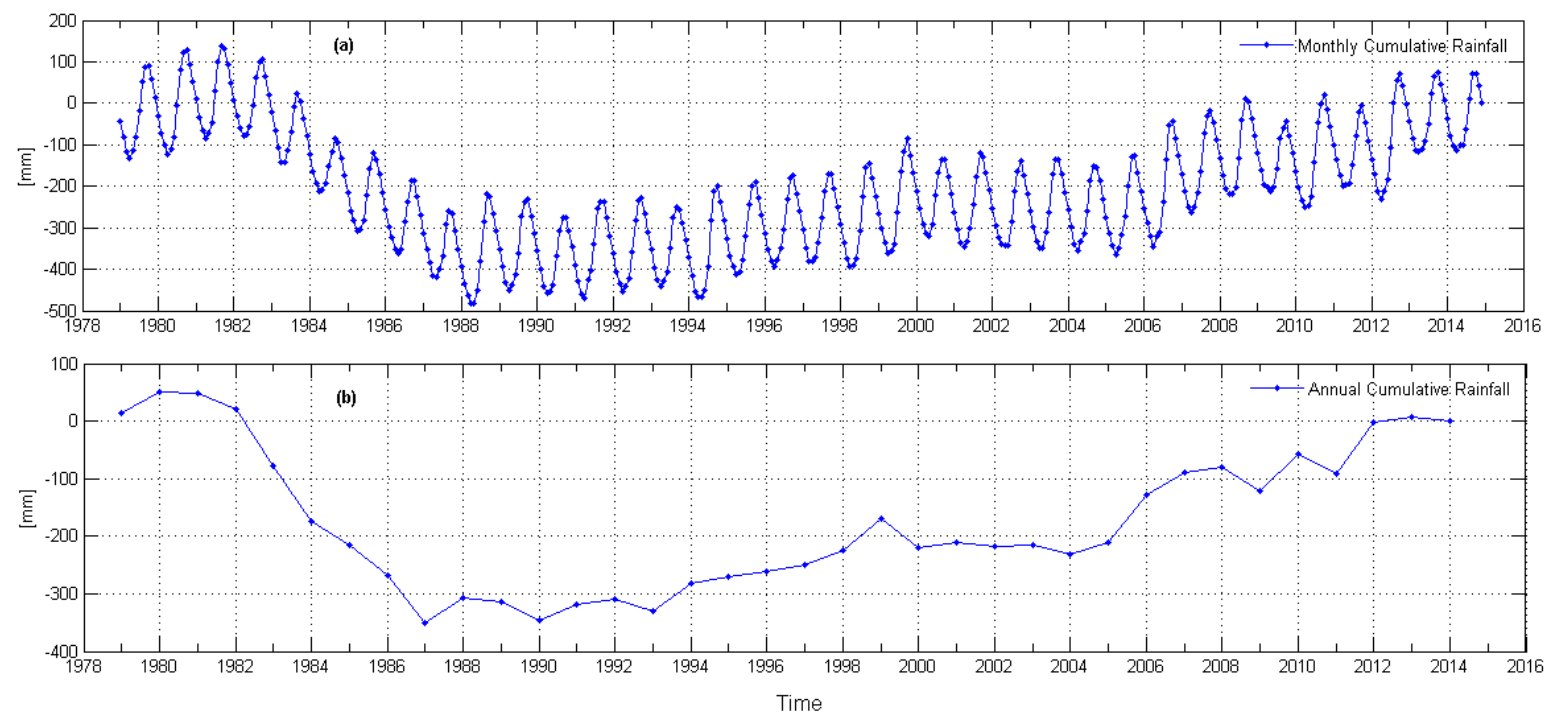

Figure 3: Cumulative rainfall anomalies averaged over LCB using the GPCP based precipitation. (a) Monthly cumulative rainfall anomaly over the basin during 1979-2014 period. (b) Annual cumulative rainfall anomaly over the basin during 1979-2014 period.

222

Santos et al., 2010; Vicente-Serrano, 2006; Rouault and Richard, 2003; Hayes et al., 1999; Komuscu, 1999). In sum, we used precipitation and soil moisture data, covering a 35-year period to quantify drought frequency (how often a drought event occurs) and severity (the intensity or strength of a drought event) for all drought categories (meteorological, agricultural, and

\section{Data and Method}

\subsection{Data}

\subsubsection{GRACE-Derived Terrestrial Water Storage (TWS) Changes}

Gravity Recovery and Climate Experiment (GRACE, Tapley et al., 2004) Release-05 (RL05) spherical harmonic coefficients from Center for Space Research (CSR) for the period of April 2002 to October 2014 were used in this study to compute changes in TWS. The CSR RL05 gravity field solutions, which are truncated at degree and order 60 were retrieved from the open access files available at http://icgem.gfz-potsdam.de/ICGEM/shms/monthly/csr-rl05/. These spherical harmonic coefficients suffer from signal attenuation and satellite measurement errors leading to noise in the higher degree coefficients (Landerer and Swenson, 2012; Swenson and Wahr, 2002). As a first step in the processing, the degree 2 coefficients were replaced with estimates from satellite laser ranging (Cheng et al., 2013) while the degree 1 coefficients provided by Swenson et al. (2008) were used. This was necessary since GRACE does not provide 
changes in degree 1 coefficients (i.e., $C_{10}, C_{11}$, and $S_{11}$ ), and is also affected by large tide-like aliases in the degree 2 coefficients (i.e., $C_{20}$ ). Secondly, after removing the long term mean, DDK2 de-correlation filter (Kusche, 2007) was applied on the GRACE monthly solutions in order to reduce the effect of correlated noise. Practically, non-isotropic filters such as the DDK2 (Kusche, 2007) accommodate better the GRACE error structure when compared to the conventional isotropic Gaussian filter (see, e.g., Werth et al., 2009). We point out briefly that there are no standard filtering procedures as most GRACE users would largely prefer the most convenient and easy-to-implement approaches. However, the filtering process can be significantly improved by using decorrelation filters, which unlike the Gaussian filter, fits better the noise in the data (e.g., Belda et al., 2015). The filtered monthly solutions were then converted to equivalent water heights on a $1^{\circ} \times 1^{\circ}$ grid using the approach of Wahr et al. (1998):

$$
\triangle W(\phi, \lambda, \xi)=\frac{R \rho_{a v e}}{3 \varrho_{w}} \sum_{l=0}^{l_{\max }} \frac{2 l+1}{1+k_{l}} \sum_{m=-l}^{l} P_{l m}(\phi, \lambda) \triangle Y_{l m}(\xi)
$$

where $\triangle W$ is equivalent water height (hereafter TWS) for each month in time $(\xi)$, and where $\phi$ and $\lambda$ are the latitudes and longitudes, respectively. $R$ is the mean radius of the Earth (i.e., $6378.137 \mathrm{~km}), \rho_{\text {ave }}$ is the average density of the Earth $\left(5515 \mathrm{~kg} / \mathrm{m}^{3}\right), \varrho_{w}$ is the average density of water $\left(1000 \mathrm{~kg} / \mathrm{m}^{3}\right), k_{l}$ is the load Love numbers of degree $l, P_{l m}$ are the normalized spherical harmonic functions of degree $l$ and order $m$ with $l_{\max }=60$ and $\triangle Y_{l m}$ are the normalized complex spherical harmonic coefficients after subtracting the long term mean. Since the effect of the DDk2 filter whose radius coincides with $340 \mathrm{~km}$ of the Gaussian filter leads to attenuation of the signal amplitude (e.g., Wouters and Schrama, 2007; Baur et al., 2009), a scaling factor obtained from Global Land Data Assimilation System (GLDAS, Rodell et al., 2004) derived terrestrial water storage content (see details in Section 3.1.7) was computed in a manner similar to Landerer and Swenson (2012). This scaling factor was applied to the GRACEderived TWS values in order to restore the geophysical signal loss caused by the impact of the DDK2 decorrelation filter. Apparently, the use of GRACE data has progressed in the direction of full scale hydrological applications and water resources monitoring (see Wouters et al., 2014). Thus, accounting for the effect of the filter in the transformed GRACE observations becomes essential as the signal attenuation will become an error in the residual in regional water balance or might serve as a constraint in water budget closure (see Landerer and Swenson, 2012). The rescaled monthly TWS grids had a few random gaps of up to 12 months in between that were filled through interpolation. This is particularly important for the regionalisation process, 
which requires continuous spatio-temporal data.

\subsubsection{Tropical Rainfall Measuring Mission (TRMM) Data}

Rainfall observations from TRMM 3B43 (Huffman et al., 2007; Kummerow et al., 2000) provide good estimates of rainfall magnitude not detected by other satellite precipitation products. In West Africa for example, Nicholson (2013) had reported that TRMM validation using in-situ data showed zero bias, having a root mean square error (RMSE) of 0.7 and $0.9 \mathrm{~mm} /$ day for the seasonal and August rainfall, respectively. Specifically, TRMM $3 \mathrm{~B} 43$ version 7 , which has a global coverage (i.e., $50^{\circ} \mathrm{S}$ and $50^{\circ} \mathrm{N}$ ) provides monthly precipitation estimates at a spatial resolution of $0.25^{\circ} \times 0.25^{\circ}$ and has been significantly improved (e.g., Duan and Bastiaanssen, 2013b). Due to its spatial resolution and bias with in-situ observations, we used TRMM 3B43 to estimate monthly and seasonal rainfall in the LCB. The data covering the period 1998-2013 was used and is available at the National Aerospace and Space Administration (NASA) Goddard Space Flight Center (GSFC) website (http://disc.gsfc.nasa.gov/datacollection/TRMM3B43-V7.shtml).

\subsubsection{Global Precipitation Climatology Project (GPCP)}

The $2.5^{\circ} \times 2.5^{\circ}$ global grids of monthly estimate from GPCP version 2.2 precipitation data set (e.g., Huffman et al., 2009; Adler et al., 2003) is a merged satellite-based product (includes satellite microwave and infrared data) that is adjusted by the use of rain gauge analysis. Unlike Ethiopia and some other countries in East Africa where TRMM is completely inconsistent with GPCP (Paeth et al., 2012), the GPCP rainfall product is highly correlated and consistent with TRMM in the region and is used here for the spatio-temporal analysis of drought in the LCB. The GPCP version 2.2 data, covering the period of 19792015, was used since drought analysis using SPI requires data record of at least 30 years. The archived data is distributed through World Data Center and is available for download at http://lwf.ncdc.noaa.gov/oa/wmo/wdcamet-ncdc.html.

\subsubsection{Satellite Altimetry Water Level Variations}

Lake level height variations computed from TOPEX/POSEIDON (T/P), Jason-1 and Jason-2/OSTM altimetry provided by the United States Department of Agriculture (USDA) was used to study Lake Chad surface water. The data covering the period 1993 to 2015 was downloaded from www.pecad.fas.usda.gov/cropexplorer/globalreservoir and used to analyse water level variations. The time series of USDA monthly lake height variation used for the 
study have been smoothed with a median type filter in order to eliminate outliers and reduce high frequency noise. The use of altimetry-based measurements for a data deficient region such as the LCB, as stated by Coe and Birkett (2004), is beneficial since they are continuous and potentially available few days after measurement. That is quite unlike gauge data that are irregular and difficult to acquire due to government policies and bureaucracies.

\subsubsection{Climate Prediction Center (CPC) Soil Moisture}

The monthly CPC soil moisture data version 2 (Fan and Dool, 2004) with spatial resolution of $0.5^{\circ} \times 0.5^{\circ}$ for the period between 1979 to 2014 was used in this study to investigate water availability through standardised soil moisture index (SSI). The data, which is model-based is derived from monthly global rainfall data that uses more than 17000 rain gauges worldwide and monthly global temperature from reanalysis. In addition, the data has been used to extract climate teleconnection patterns such as the El-Niño Southern Oscillation and long term trends (Fan and Dool, 2004). The data is freely available at NOAA (http://www.esrl.noaa.gov/psd/data/gridded/data.cpcsoil.html) for download.

\subsubsection{Climate Indices}

Relevant and well known global climate teleconnections indices such as El-Niño Southern Oscillation (ENSO), Atlantic Multi-decadal Oscillation (AMO), and Atlantic Meridional Mode (AMM) have been associated with precipitation patterns (see, e.g., Giannini et al., 2003; Nicholson, 2013; Giannini et al., 2013; Paeth et al., 2012), important factors that regulate the formation and persistence of drought events in the Sahel and some countries of West Africa. These indices, covering the period 1979-2014, were used to examine the relationship and possible links of observed temporal evolutions of droughts in LCB with coupled atmosphereocean system and perturbations of nearby oceans. We point out briefly that other ENSO indices such as Nino3.4 and Nino4.0 exist but we used Multivariate Enso Index-MEI (hereafter called ENSO) since it comprises six other variables over the Pacific coupled with atmospheric anomalies. The climate indices used in this study can be downloaded from National Oceanic \& Atmospheric Administration (NOAA) websites (e.g., http://www.cpc.ncep.noaa.gov).

\subsubsection{Global Land Data Assimilation System (GLDAS)}

GLDAS (Rodell et al., 2004) derived monthly total water storage content (TWSC) at $1^{\circ} \times 1^{\circ}$ spatial resolution was used to rescale the GRACE-derived TWS change in order to remedy the signal loss due to filtering. GLDAS is unique because it integrates both satellite 
and in-situ data to produce optimal fields of land surface states and fluxes (Rodell et al., 2004). The TWSC was derived from summing all the layers from Noah 2.7.1 land surface model of GLDAS (i.e., all the soil moisture layers including the canopy water storage). This land surface model (i.e., the NOAH component of GLDAS) showed a good agreement with GRACE-derived TWS in West Africa, indicating a coefficient of determination $\left(R^{2}\right)$ of 0.85 (Ndehedehe et al., 2016a). However, the averaged TWSC and GRACE-derived TWS in the LCB showed a relatively stronger agreement (i.e., $R^{2}$ of 0.88 ) with a root mean square error of 19.83 (see Appendix A3, Fig. 17). While it is important to acknowledge that the GLDAS model incorporates soil moisture and plant canopy surface water storage, it does not include surface and groundwater components. However, previous studies have reported a good agreement between GLDAS-TWSC and GRACE-derived TWS at basin scale (e.g., Moore and Williams, 2014). To derive the scale factor, TWSC was filtered using the DDK2 filter similar to GRACE observations. Thereafter, the ratio of the DDK2 filtered TWSC to the unfiltered and synthesised TWSC was used to derive a scale factor. This scale factor, which measures the impact of DDK2 filter on GRACE-observations, was then applied to the gridded TWS values similar to previous studies (see, e.g., Long et al., 2015; Landerer and Swenson, 2012). GLDAS-derived TWSC covering the years 2001-2014 was obtained from the open access file available at http://grace.jpl.nasa.gov/data/get-data/land-water-content/.

\subsubsection{Sea Surface Temperature (SST)}

SST version 2 (Reynolds et al., 2002) data was downloaded from the website (http://www.es rl.noaa.gov/psd/data/gridded/data.noaa.oisst.v2.html) of the National Oceanic and Atmospheric Administration (NOAA). The period covered is from 2002 to 2014. The SST averaged of the Atlantic Ocean $\left(30^{\circ} \mathrm{S}-30^{\circ} \mathrm{N}\right.$ and $\left.70^{\circ} \mathrm{W}-20^{\circ} \mathrm{E}\right)$ was used in this study to investigate its relationship with annual cycles of rainfall over the basin.

\subsubsection{Satellite Image Analysis}

Landsat 7 Enhanced Thematic Mapper plus (ETM+) and Landsat 8 imageries were downloaded from the United States geological surveys website (http://glovis.usgs.gov/). The imageries for 2000, 2003, and 2015 in the Lake Chad area were clipped and classified using Iterative Self-Organizing Data Analysis Technique Algorithm (ISoData) technique proposed by Ball and Hall (1965). The method is an unsupervised classification method that uses an iterative clustering algorithm and allows the number of clusters to be dynamically determined. The surface area of the Lake at different epoch was estimated using the classified pixels rep- 
resenting water bodies. Estimating the recent surface area is critical to understanding the desiccation story of the basin in recent times. It is also important to evaluate the wet/dry regimes of the basin in the last decade.

\subsection{Method}

\subsubsection{Standardised Drought Indices}

Drought phenomenon is usually expressed using standardised indices for example, standardised precipitation index (SPI, McKee et al., 1993) and standardised runoff index (Shukla and Wood, 2008) amongst others. The SPI is a very popular drought index. It is normalized so that wetter and drier climates can be represented in a similar way and can be calculated for other water variables and hydrological quantities such as snowpack, reservoir, streamflow, soil moisture, and ground water (McKee et al., 1993). In this study, we utilised two variables (rainfall and CPC model soil moisture) to implement a non-parametric standardised multivariate drought index in order to compensate for the weakness of single drought index as argued by Hao and AghaKouchak (2014). The mathematical framework of this non-parametric multivariate standardised drought index (MSDI) and other single drought indicators (e.g., SPI and SSI) is fully documented by Farahmand and AghaKouchak (2015). These drought indicators adopt empirical method to determine the marginal probability of precipitation and other variables such as soil moisture, evapotranspiration, and runoff. The MSDI combines two hydrological quantities to derive a composite drought index, which can be described as a multivariate prototype of the popular SPI (AghaKouchak, 2015). Recently, the MSDI has been shown to be a statistically consistent drought index (Huang et al., 2015) and is employed here for the first time in the region. The joint distribution of two variables $\mathrm{X}$ and $\mathrm{Y}$ expressed as (Hao and AghaKouchak, 2013)

$$
P(X \leq x, Y \leq y)=p
$$

where $p$ represents the joint probability of any two variable (e.g., rainfall and soil moisture). The joint probability is then used to define the MSDI as

$$
M S D I=\phi^{-1}(p)
$$

where $\phi^{-1}$ is the standard normal distribution function. For the bivariate case, the Gringorten plotting position formula (see Farahmand and AghaKouchak, 2015; Hao and AghaKouchak, 2014) is used to estimate the empirical joint probability. The empirical Gringorten plotting position is expressed as: 


$$
p\left(x_{k}, y_{k}\right)=\frac{m_{k}-0.44}{n+0.12}
$$

where $n$ is the number of the observation and $m_{k}$ is the number of times which the pair $\left(x_{i}, y_{i}\right)$ occur for $x_{i} \leq x_{k}$ and $y_{i} \leq y_{k}(1 \leq i \leq n)$. Eq. 4 is used in Eq. 3 to compute the MSDI while the standardised precipitation index (SPI) and standardised soil moisture index (SSI) are also estimated using the univariate form of Eq. 4. Thus, we combined averaged GPCP rainfall and soil moisture to derive time series of MSDI, in addition to the single drought indicators across different time scales (i.e., 1, 3, 6, and 12 months). The drought classification and extreme rainfall events used in this study are based on the description of McKee et al. (1993) (Table 1).

As discussed earlier in Section 2, localising drought signals has been a major limitation in drought studies. Hence, the ICA method (see details in Section 3.2.2) was used to decompose the gridded time series of computed SPI and SSI at 3, 6, and 12 month scales into independent modes (i.e., temporal and spatial patterns) where drought/wet signals are localised in terms of their spatial and temporal variations. The statistically significant modes of variability identified in the LCB were analysed further. Essentially, this statistical decomposition of meteorological and land surface state variables (i.e., rainfall and soil moisture) into spatial and temporal patterns allow the extraction of climate teleconnection patterns and other relevant coupled ocean atmosphere patterns that are related to the observed wet and dry periods in the basin. Prior to decomposing gridded rainfall and soil moisture drought indicators into spatial and temporal patterns, the spatially averaged time series of each of the two datasets were used to compute time series of SPI and SSI. That provides the opportunity to compare the results of the two approaches (i.e., the decomposed gridded drought indicators and time series of averaged indicators over the basin). To understand the relationship of climate teleconnection indices with ICA-derived temporal variability of drought patterns, Pearson correlation analysis was applied. The SPI values at 3,6, and 12 month scales for all first and second ICA modes, were selected for this correlation with global climate teleconnection indices (i.e., AMO, AMM, and MEI). This choice is based on the theoretical assumption that the first and second ICA modes have relatively stronger dominant modes of variability. A student T-test was then used to calculate the significance of the correlation at $95 \%$ confidence level. 
Table 1: Drought classification and extreme rainfall/soil moisture events based on McKee et al. (1993) classification system.

\begin{tabular}{ll}
\hline Description & Threshold \\
\hline Extreme wet & +2.0 and above \\
Very wet & +1.5 to +1.99 \\
Moderately wet & +1.0 to +1.49 \\
Near normal & -0.99 to +0.99 \\
Moderate drought & -1.0 to -1.49 \\
Severe drought & -1.5 to -1.99 \\
Extreme drought & -2.0 or less \\
\hline
\end{tabular}

\subsubsection{Independent Component Analysis (ICA)}

The ICA (see, e.g., Ziehe, 2005; Cardoso and Souloumiac, 1993; Cardoso, 1991; Common, 1994; Cardoso, 1999) technique (see further details in Appendix A2) was used to decompose a data matrix $\mathbf{X}$, into spatial maps $\mathbf{M}$, and temporal patterns $\mathbf{T}$, as:

$$
\mathbf{X}_{S P I / S S I / T W S}(x, y, t)=\mathbf{T M}
$$

where $(x, y)$ are grid locations, $t$ is the time in months. $\mathbf{T}$ is unit-less since it has been normalised using its standard deviation while the corresponding spatial patterns $\mathbf{M}$, have been scaled using the standard deviation of its independent components (i.e., T). In this study, we used the JADE (see further details in Appendix A2) algorithm (available at http://perso.telecomparistech.fr/cardoso/Algo/Jade/jadeR.m) to decompose standardised drought indicators (i.e., the gridded SPI and SSI data) and GRACE-derived TWS into spatial maps and temporal patterns. Each ICA mode (a pair of the independent components and spatial patterns) of variability is a combination of the temporal and spatial patterns and are usually interpreted together (i.e., the unit-less temporal evolution is multiplied with the spatial pattern in order to obtain the actual values of SPI, SSI, and TWS).

\subsubsection{Trends and Correlation Analysis}

The trends in observed temporal evolutions of TWS and Lake Chad water level variations were estimated using the least squares method. Further, we examined the relationship of climate teleconnections with observed temporal SPI patterns (i.e., at 3, 6, and 12 months aggregation) using the linear correlation coefficient $(r)$. The significance of observed correlations 
were tested at $95 \%$ confidence level using the Student-t distribution test as

$$
t=r \sqrt{\frac{n-2}{1-r^{2}}}
$$

where $n$ is the total number of given observations for the data.
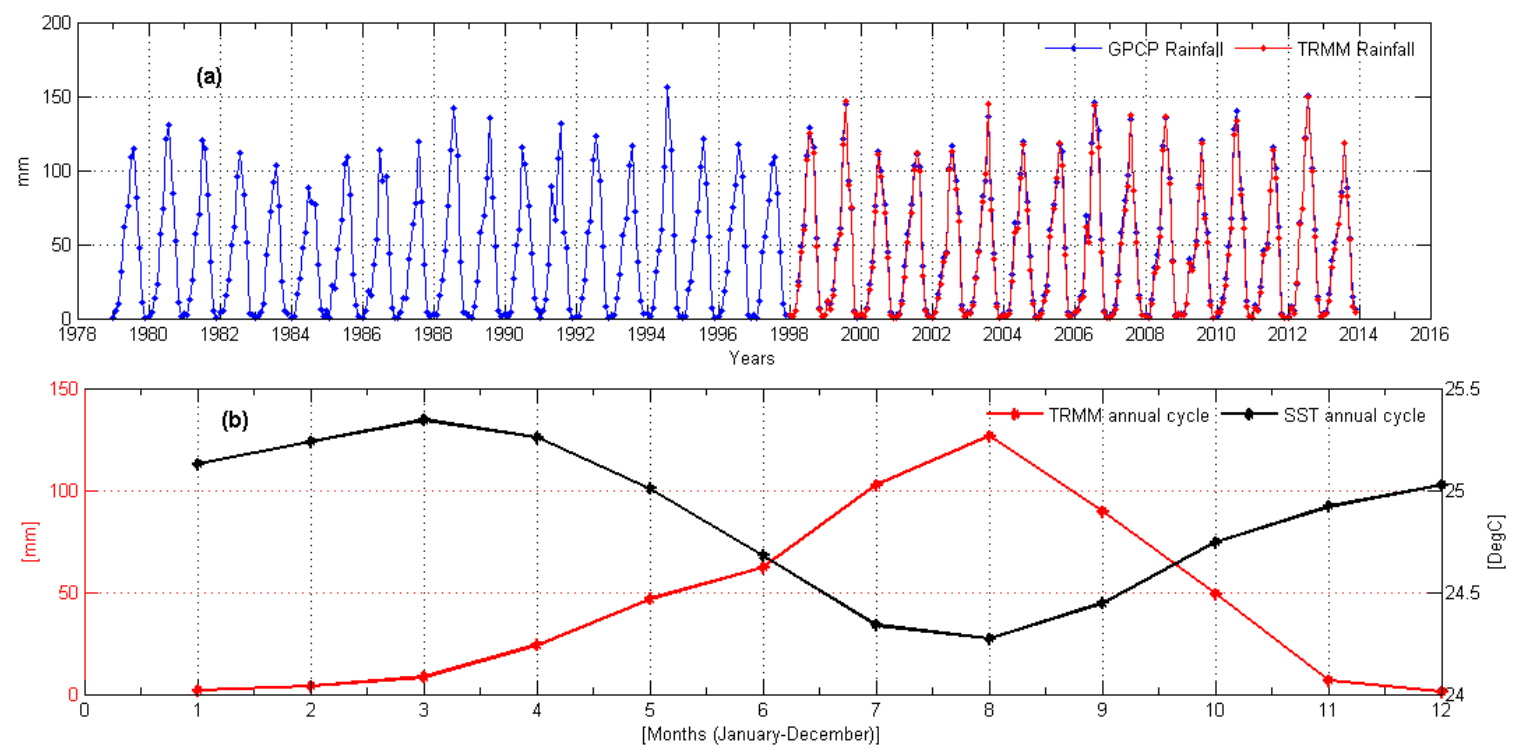

Figure 4: Averaged monthly rainfall over Lake Chad basin and annual cycles of TRMM-based precipitation and sea surface temperature (SST). (a) Time series of spatially averaged rainfall over Lake Chad basin using GPCP version 2.2 (1979 - 2013) and TRMM 3B43 based precipitation (1998 - 2013) (b) Long term mean annual cycle of rainfall over Lake Chad basin using TRMM 3B43 based precipitation and annual cycle of SST data averaged over the Atlantic Ocean $\left(30^{\circ} \mathrm{S}-30^{\circ} \mathrm{N}\right.$ and $\left.70^{\circ} \mathrm{W}-20^{\circ} \mathrm{E}\right)$.

\section{Results and Discussions}

\subsection{Seasonal Rainfall Patterns over the Lake Chad Basin (LCB)}

TRMM 3B43 version 7 precipitation product was used for the seasonal analysis and long term annual cycle while the GPCP version 2.2 precipitation data was used for the drought analysis because of its duration (35 years). A 35-year data meets the criteria for SPI since a 30-year data or less shortens the sample size and undermines the confidence in its usage (e.g., Svoboda et al., 2012). Comparing the TRMM and GPCP based precipitation products, the spatially averaged GPCP product was consistent (indicated a linear correlation of 0.99) with the spatially averaged TRMM product. This near-perfect correlation is expected since TRMM is adjusted by rain gauge observations, most of which are included in the GPCP datasets. Despite the differences in the spatial resolutions of these two precipitation products, their strong agreement over the LCB can be useful in future studies to characterise uncertainties in 
water budget analysis. Although no notable trend is observed in the spatially averaged rainfall over the basin, we observe a recent pronounced maximum peak in 2012 that is similar to other extreme wet years, for example, 1988, 1994, 1999, 2003, and 2006 (Fig. 4a). The lowest annual rainfall peak observed in 1984 (Fig. 4a) is consistent with the well known drought that ravaged the African continent during the 1982-1984 period (e.g., Masih et al., 2014). The annual cycle of precipitation over LCB indicates a peak in August while the seasonality of SST shows an opposite phase with rainfall (Fig. 4b). Most parts of the LCB lies in the Sahel region, and the impact of SST variability on rainfall has been reported (Mohino et al., 2011; Paeth et al., 2012; Lebel and Ali, 2009). Rainfall decline in the coastal West African countries has been associated with cold SST along the Atlantic and warm SST in the eastern tropical Pacific while decadal rainfall trends in the Sahel is assumed to be influenced by a combination of multiple low-frequency SST signals (e.g., Rodrguez-Fonseca et al., 2011).

Moreover, the seasonal analysis show that maximum rainfall (temporal variations) comes between July and September with a maximum averaged rainfall of about $150 \mathrm{~mm}$ while other seasons have less than a $100 \mathrm{~mm}$ of rainfall (Fig. 5, right). The spatial distribution of rainfall indicates a maximum of about $250 \mathrm{~mm}$ of rainfall towards the southern part of the basin and more than $300 \mathrm{~mm}$ outside the conventional basin area (Fig. 5, left). Comparatively, the GPCP version 2 seasonal rainfall patterns over the basin also show similar temporal and spatial patterns with the July-September period indicating relatively low pronounced amplitudes of rainfall (e.g., $1983-1984,1987$, etc.) in the temporal variations due to extreme drought conditions (see Appendix A1, Fig. 16). Generally, the July-September rainfall (i.e., using the GPCP data) in the basin is the dominant rainfall as the most pronounced maximum peaks correspond to those of Fig. 5. Overall, the seasonal rainfall patterns over the basin, clearly show the dichotomy between the northern section (having low rainfall) and the southern band (which receives more rainfall especially between July and September) (Fig. 5). This seasonal picture of rainfall in the basin is crucial as it has the capacity to enhance the assessment of the basin's hydrology. The knowledge of the basin's climatology, in terms of seasonal rainfall can enhance our interpretation of the standardised drought indices.

\subsection{Drought Characteristics Over the Lake Chad Basin (LCB)}

\subsubsection{Time Series of Standardised Drought Indicators}

The standardised drought indicators (i.e., SPI, SSI, and MSDI) for the LCB were computed at 1, 3, 6, and 12 month cumulations using spatially averaged GPCP and CPC soil moisture 

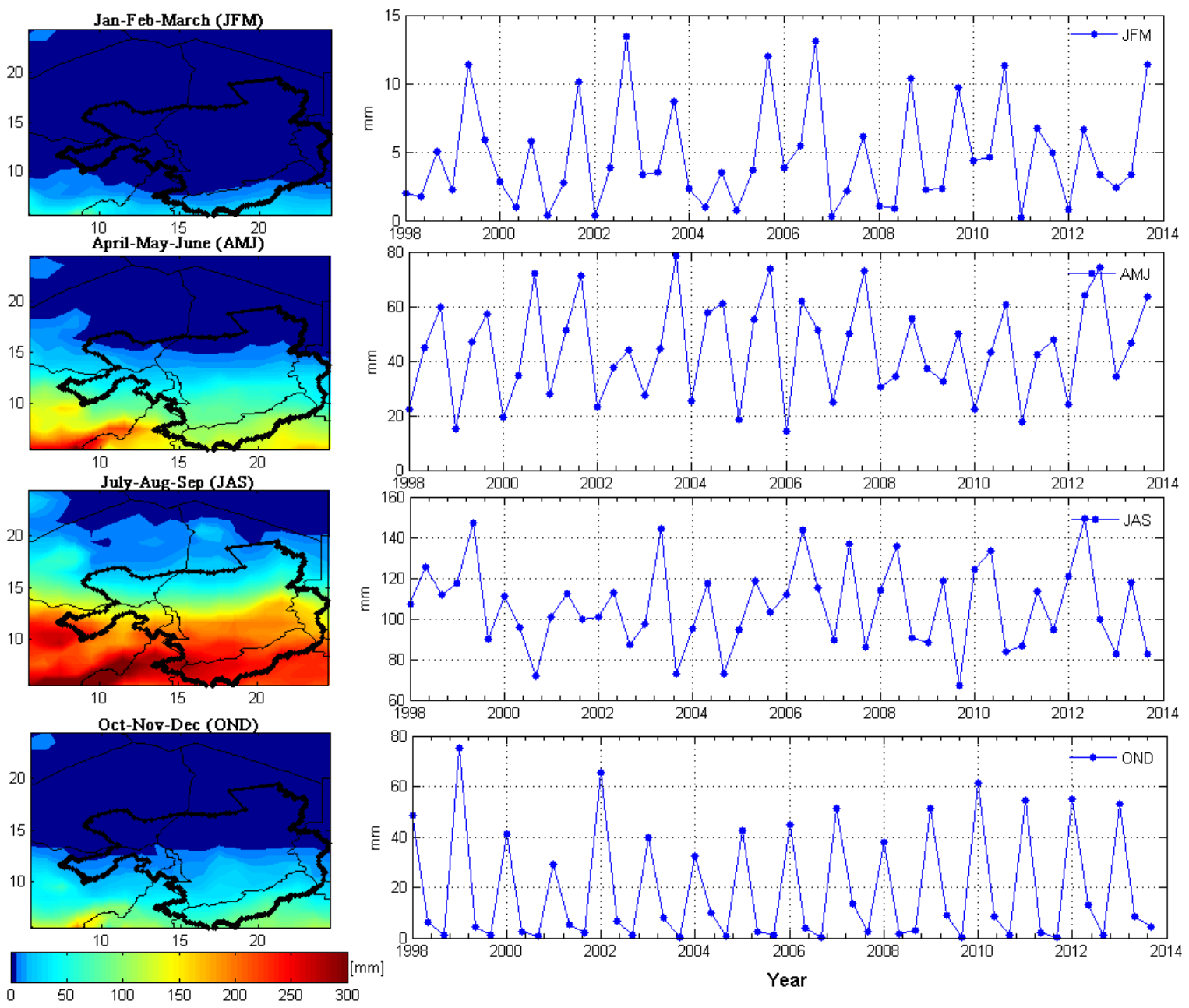

Figure 5: Seasonal rainfall analysis for Lake Chad Basin $\left(5.5^{\circ} \mathrm{N}-24.5^{\circ} \mathrm{N}\right.$ and $\left.5.5^{\circ} \mathrm{E}-24.5^{\circ} \mathrm{E}\right)$ using TRMM satellite data for the period 1998 - 2013. Spatial patterns (left) and temporal patterns (right) are averaged over the geographical boundary describing the spatial extent of Lake Chad basin used in this study. The inset (i.e., the solid black line) is the conventional basin boundary.

data over the basin. Results show that shorter time scales (e.g., 1 and 3 month cumulations) have high drought frequencies (Fig. 6a-b). The frequency reduces with increase of time scales (e.g., 6 and 12 month cumulations) (Fig. 6c-d). According to Komuscu (1999), this kind of relationship implies that the index responds more slowly as the time scales increases. Consistent decrease in SPI and MSDI values were observed from 1979 to 1985 (Fig. 6) but with recovery in 1984 at 3 and 6 months scale. The strong decline of SPI and MSDI within this period coincides with the hydrological drought record of the basin, which showed a dramatic loss of $15138 \mathrm{~km}^{2}$ in the surface area of Lake Chad (see, Alfa et al., 2008). The MSDI and SSI show drought persistence in 1990/1991 at all scales (Fig. 6a-d); 1998 at 3 and 6 months (Fig. 6b-c); and 2009 at 6 and 12 months (Fig. 6c-d). The drought years as indicated in the 

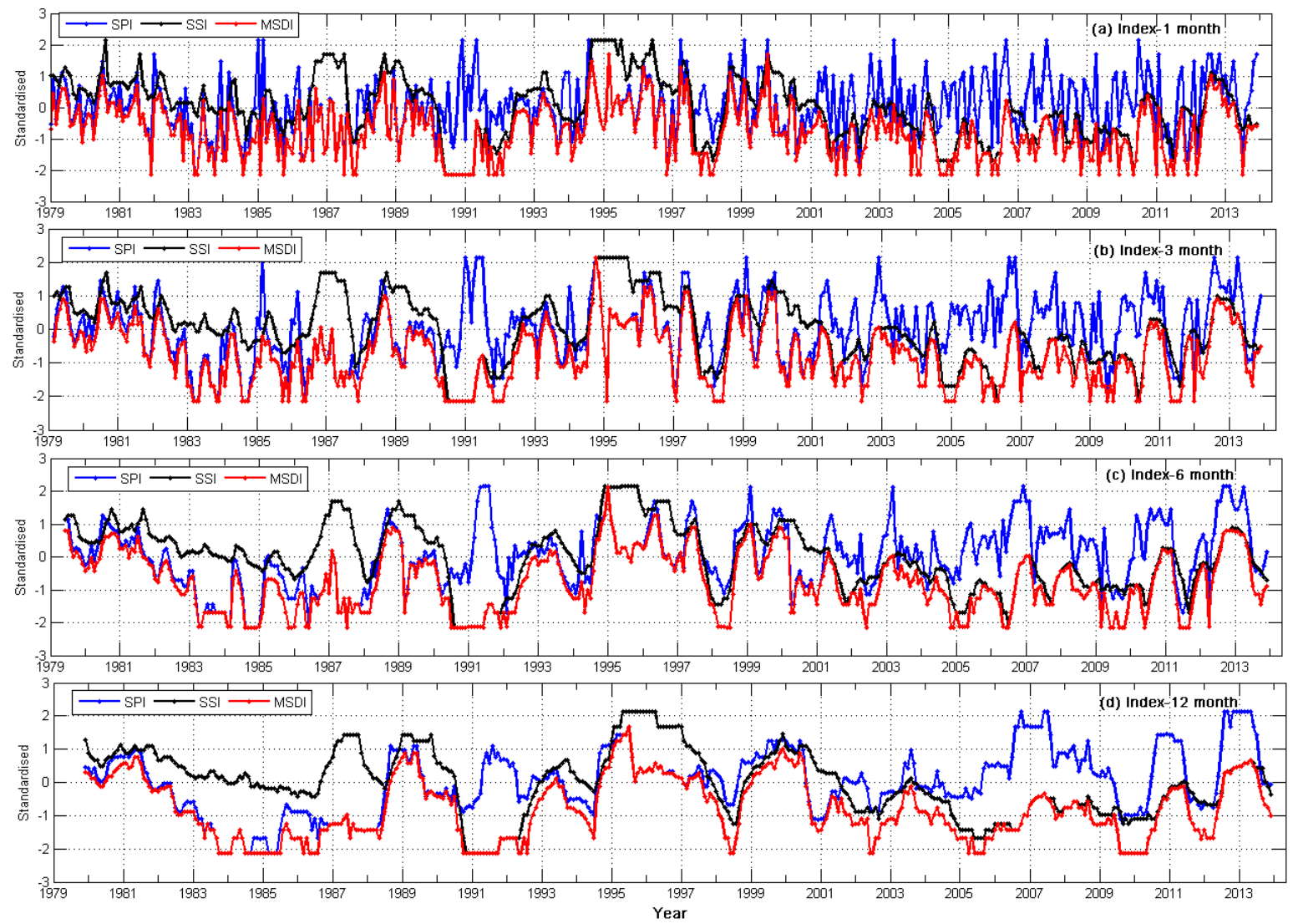

Figure 6: Time series of standardised drought indicators (i.e., SPI, SSI, and MSDI) for Lake Chad basin using averaged GPCP and CPC soil moisture data covering the period 1979 - 2013 (i.e., over the basin). The MSDI is derived through the combination of GPCP based precipitation and CPC based soil moisture data. These standardised drought indicators are based on empirical probability, different from the gamma distribution function used in the SPI case of McKee et al. (1993).

standardised drought indicators are generally consistent with observed decline in the northern pool of the Lake as previously reported by Lemoalle et al. (2012). In addition, the observed wet (e.g., 1988 and 1994) and dry (e.g., 1983 - 1985) years (Fig. 6) are consistent with the records of observed water levels at Kindjeria (i.e., at the northern section of LCB) as reported in a previous study by Lemoalle et al. (2012). They noted that the northern pool gets flooded during extreme wet periods and completely dry for several years due to incessant drought conditions. Similar patterns in the behaviour of surface waters (e.g., Lakes) vis-à-vis drought and 
terms of severity). But the cases are significant enough to impact negatively on the agrarian system and food security conditions of the basin where agriculture is predominantly rain-fed.

Furthermore, extreme wet conditions in 1987/1988 (all through the year), and 1994/1995 show strong persistence in wetness by SSI (Fig. 6a-d). On the contrary, SPI and MSDI showed drought conditions in 1987 while in 1995 they indicated that the wet conditions actually ended, unlike SSI, which indicated that the severe wet conditions that started in late 1994 persisted even till 1996 (Fig. 6b-d). This inconsistency is probably caused by intense rainfall occurring within few months while the remaining months of the year are consistently dry. The SPI values (i.e., at 1 and 3 months cumulation) tend to be very high during the $2003-2013$ period (Fig. 6a-b), and are consistent with the findings of Okonkwo et al. (2013) whose report showed increase in SPI values between 2002 and 2011 in the basin. However, the SSI and MSDI show longer drought durations in late 2004 (Fig. 6a-b) and 2005 (Fig. 6c-d). In the drought assessment done so far using the three standardised indicators over the LCB, recent conditions of wetness in late 2010 and 2012/2013 captured by SPI, SSI, and MSDI (Fig. 6a-d) appear to be a dramatic deviation from the long string of frequent drought conditions observed in the basin (note that at 12 month cumulation period, only SPI indicated wet condition in 2010 while SSI and MSDI showed a recovery from drought condition). This period (i.e., between 2010 and 2013), which also coincides with increased water level in Lake Chad as shown in Section 4, is largely consistent with the spatially averaged rainfall over the basin within the same period (Fig. 4a). Further, as the accumulation period increases (i.e., for SPI), soil moisture conditions tend to respond slowly to extreme wet conditions of SPI. It seems that the extreme wet condition was not sufficient enough to cushion the deficit conditions of soil moisture in the basin. For instance, when we evaluate SPI (i.e., 12 month scale) values of 1991, $2006-2007$ and 2012 - 2013 periods against SSI and MSDI (i.e., 12 month scale) values during the same period, the inconsistencies are rather obvious. SPI indicates extreme wet conditions during those periods (1991/1992 and 2006 - 2007) while MSDI and SSI show extreme drought (1991 and $2006-2007)$ and normal conditions $(2011-2013$ period) as against the extreme wet condition indicated by the SPI (2012 - 2013 period) (Fig. 6). Soil moisture deficits have been related to antecedent conditions, evaporation, seepage to groundwater, evapotranspiration, and runoff (e.g., Loon, 2015). According to Birkett (2000), Lake Chad loses about $80 \%$ of water through evaporation due to low humidity and high temperatures. Considering the fact that the basin is located in a semi-arid Sahelian environment, these factors and others (e.g., soil characteristics) may account for the observed inconsistencies between SPI and SSI. In 

into spatial and temporal patterns using the ICA technique.

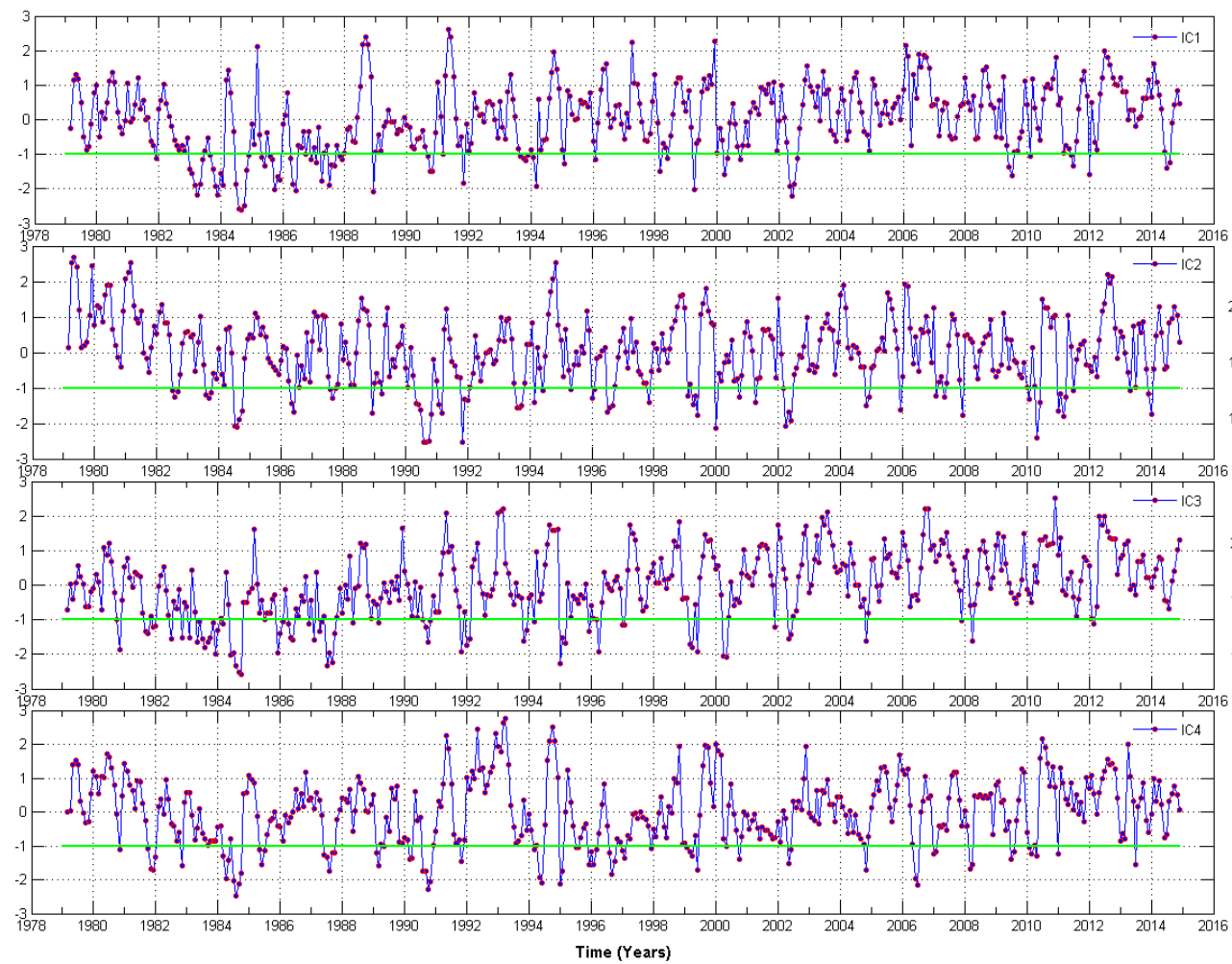

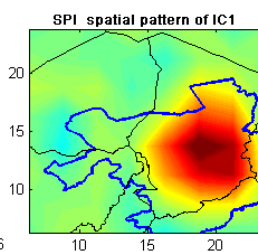
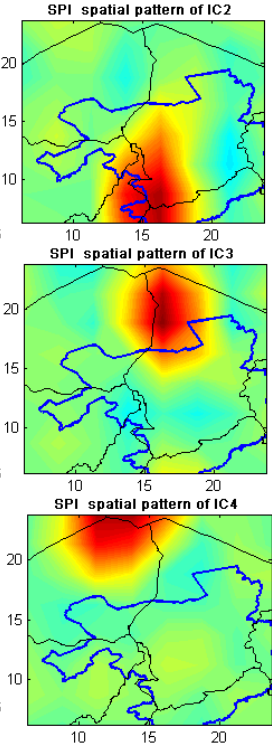

Figure 7: ICA-derived spatio-temporal SPI patterns of LCB using 3-month gridded SPI values. The SPI values are computed using GPCP rainfall product for the period 1979 - 2014. Localised spatial SPI patterns (right) corresponds to the temporal evolutions (left). The actual SPI values to be used for drought classification are jointly derived from the spatial and temporal SPI patterns. The green solid line is drought threshold.

subsequent sections we show results of the statistical decomposition of SPI and SSI signals 
Table 2: Correlation coefficients between temporal evolutions of SPI (i.e., 3, 6, and 12 months SPI scales) derived from the ICA process and global climate teleconnection indices. Correlation values in bold are significant at $\alpha=5 \%$ confidence level.

\begin{tabular}{ccccc}
\hline \multirow{2}{*}{ SPI Scale } & $\begin{array}{c}\text { Independent } \\
\text { Components }\end{array}$ & AMO & AMM & ENSO \\
\hline \multirow{2}{*}{3 month } & 1 & $\mathbf{0 . 3 1}$ & $\mathbf{0 . 3 0}$ & -0.18 \\
& 2 & -0.13 & $\mathbf{- 0 . 2 1}$ & 0.07 \\
6 month & 1 & $\mathbf{0 . 3 8}$ & $\mathbf{0 . 3 8}$ & $\mathbf{- 0 . 2 2}$ \\
& 2 & $\mathbf{- 0 . 4 5}$ & $\mathbf{- 0 . 3 3}$ & 0.18 \\
12 month & 1 & $\mathbf{0 . 5 5}$ & $\mathbf{0 . 3 8}$ & $\mathbf{- 0 . 3 4}$ \\
& 2 & $\mathbf{0 . 3 6}$ & 0.08 & -0.07 \\
\hline
\end{tabular}
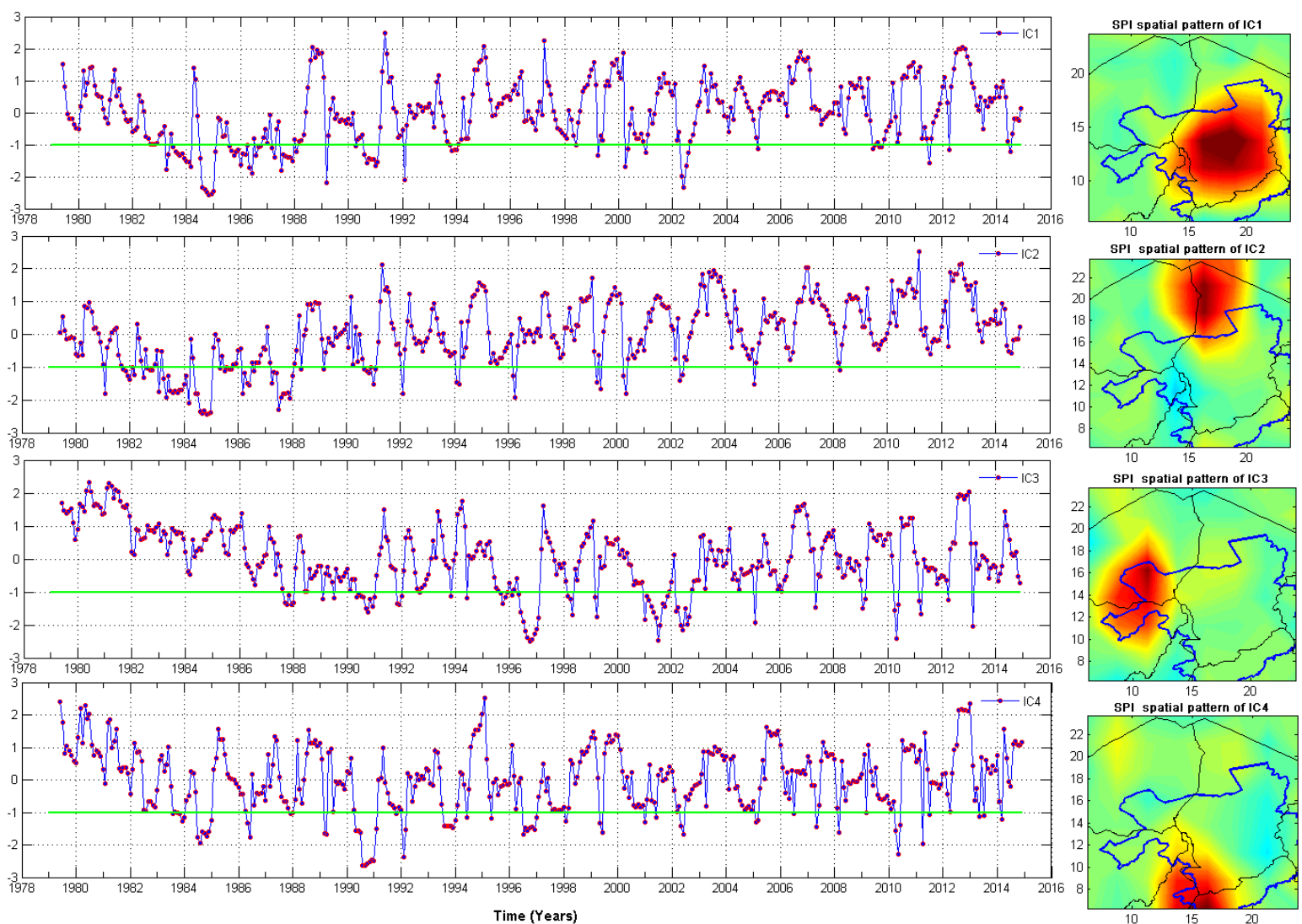

Figure 8: ICA-derived spatio-temporal SPI patterns of LCB using 6-month gridded SPI values. The SPI values are computed using GPCP rainfall product for the period 1979 - 2014. Localised spatial SPI patterns (right) corresponds to the temporal evolutions (left). The actual SPI values to be used for drought classification are jointly derived from the spatial and temporal SPI patterns. The green solid line is drought threshold.

drought patterns), however, in this section we choose these intermediate and long term scales $(3,6$, and 12 months) for the spatio-temporal drought variability since they fit in well with 

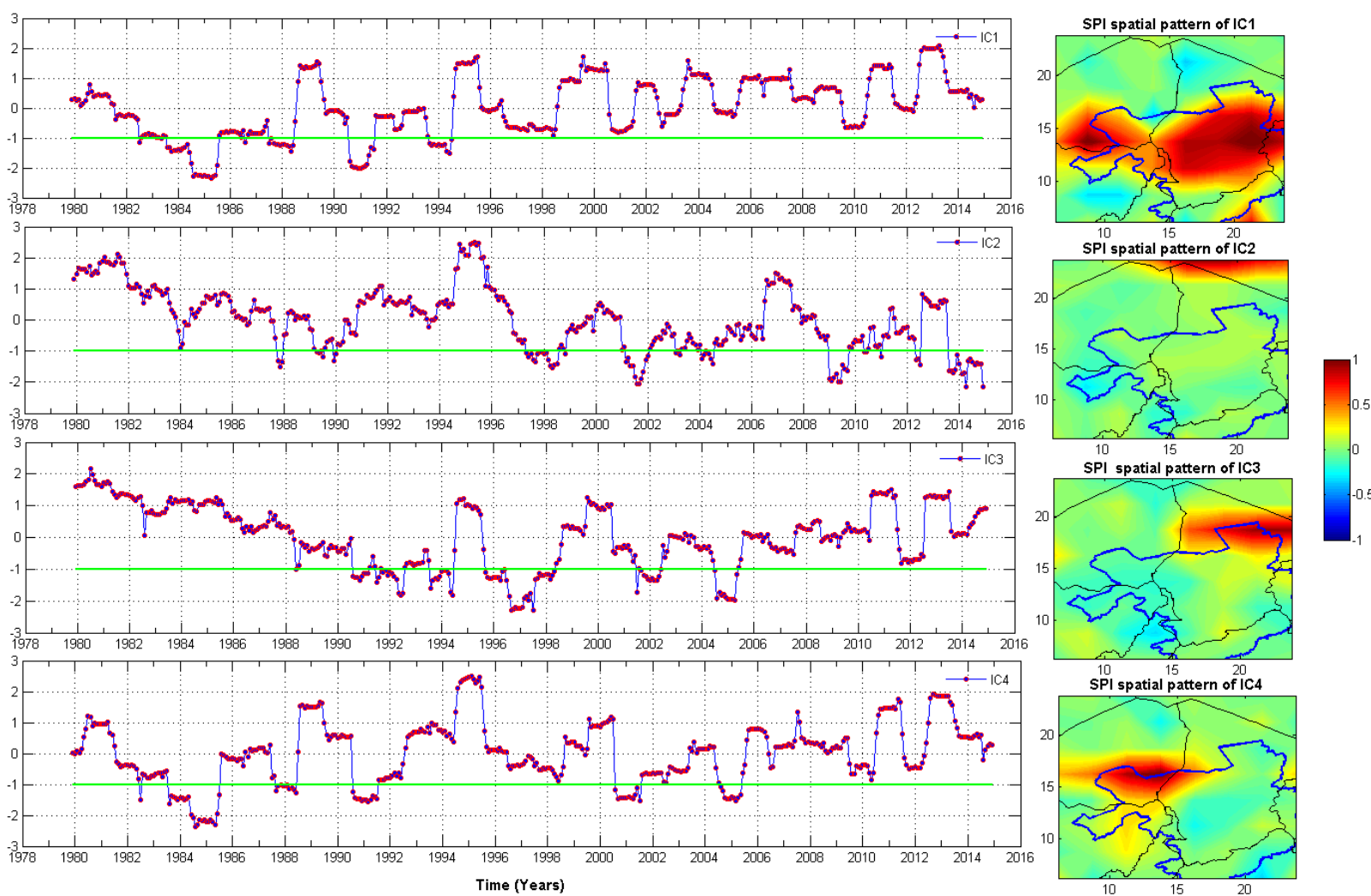

Figure 9: ICA-derived spatio-temporal SPI patterns of LCB using 12-month gridded SPI values. The SPI values are computed using GPCP rainfall product for the period 1979 - 2014. Localised spatial SPI patterns (right) corresponds to the temporal evolutions (left). The actual SPI values to be used for drought classification are jointly derived from the spatial and temporal SPI patterns. The green solid line is drought threshold.

agricultural and hydrological drought monitoring as indicated earlier in Section 2.

When comparing the temporal evolutions of SPI for 3 and 6 month time scales, a number of similar characteristics are observed. Declining SPI values from 1980 up to 1984 and extreme drought in 1984 are observed (Figs. 7 and 8) in the central part of the conventional basin. Also there is a change in drought frequency as the time scale changes. In Fig. 9, drought frequency is reduced when compared to Figs. 7 and 8 where drought frequencies are high. However, drought persistence is higher on longer time scales than short aggregation windows (see, Figs. 7-9). This is not to suggest that all cases of longer drought duration are usually related to the aggregation window. SPI aggregated over longer time scales (e.g., 12 and 24 months) are sometimes used in monitoring hydrological droughts (see e.g., Ndehedehe et al., 2016b; Li and Rodell, 2015; Lloyd-Hughes, 2012; Santos et al., 2010). But the propagation processes from meteorological to hydrological drought conditions may take some time depending on the soil surface conditions, which creates a lagged response (see IC1, Figs. 7-9). At all monthly SPI scales, we observed relatively strong drought spatial patterns towards the north and centre 

till 1985 (IC1, Fig. 9). Similar temporal pattern is also observed in the section of the basin that
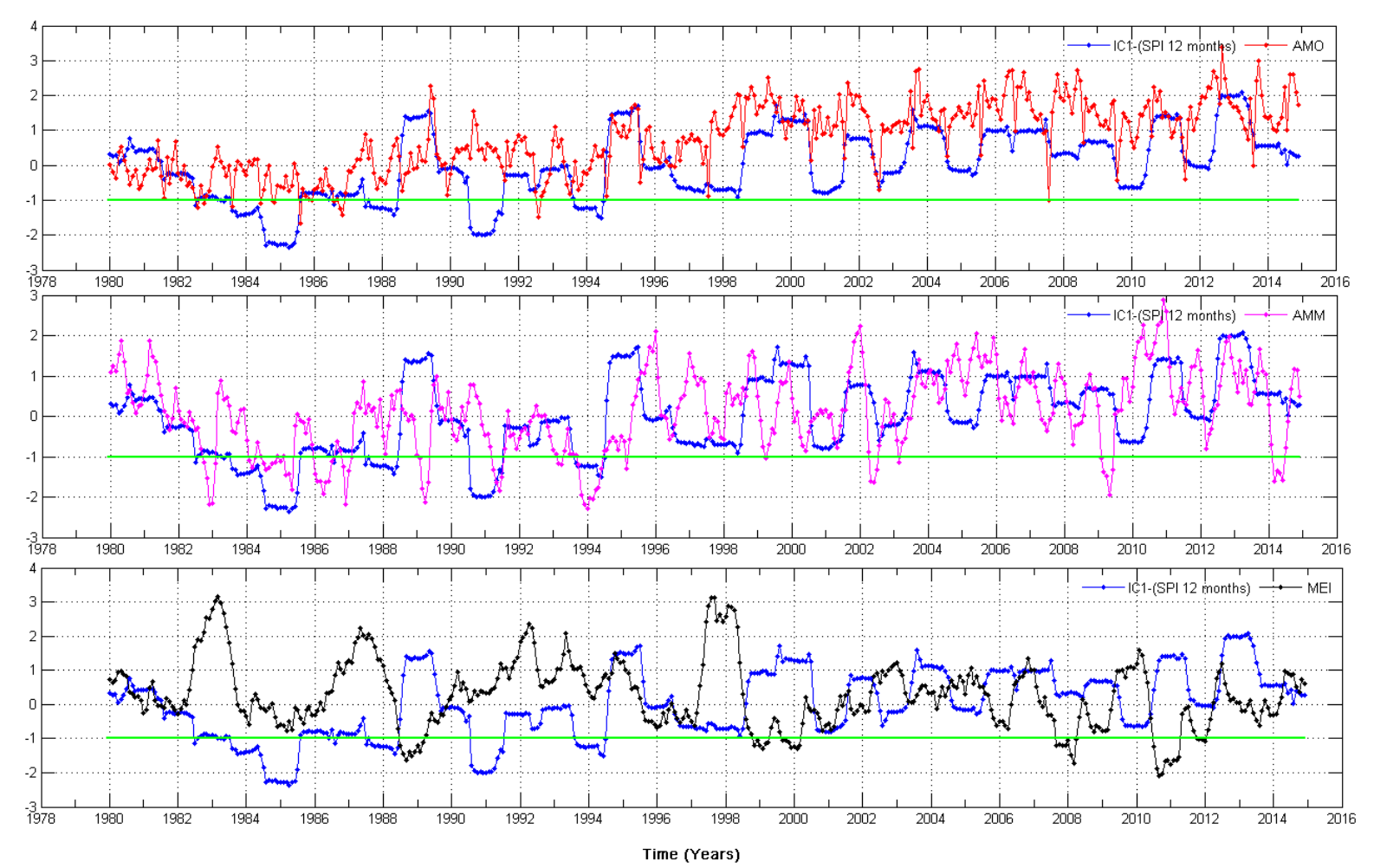

Figure 10: Influence of global climate teleconnection indices (i.e., 1979 - 2014) on temporal evolutions of hydrological droughts (i.e., 12 month SPI). The temporal drought pattern of ICA mode 1 shown in Fig. 9 are correlated with AMO (top), AMM (middle), and MEI (bottom).

of the conventional basin area and the entire basin at large. Even though we do not observe strong spatial drought patterns directly over Lake Chad, the southern part of the basin where the lake receives $\sim 95 \%$ of its alimentation via the Chari-Logone river experienced drought at 3 and 6 month scales (IC2 and IC4 of Figs. 7 and 8, respectively), that is, when the SPI values are jointly considered or interpreted together from the spatial and temporal patterns. From their temporal evolutions (i.e., IC2 and IC4 of Figs. 7 and 8 respectively), specific years such as 1984, 1990, 1992/1993, 1996, 2000, 2002, and 2010 indicate similar drought characteristics, which we attribute to strong deficit in rainfall in those years. Still on the conventional basin area, the corresponding temporal evolution of drought spatial patterns at 12-month scale (i.e., hydrological drought) indicates extreme drought conditions, which began in 1983 and persisted (1)

belongs to Niger (IC4, Fig. 9). IC2 and IC3 of Fig. 9 show SPI signals in Libya and northern Chad respectively. Apart from the extreme wet conditions of 1988, 1994, and 1998-1999 in some parts of the LCB (IC1 and IC4, Fig. 9), which was also reported by Nicholson et al. (2000), the period between late 1995 and 1997 indicates drought persistence with extreme dry 
conditions in 1996/1997 at northern Chad (IC3, Fig. 9). We point out briefly that while IC1 of Fig. 9 (i.e., Central Chad) showed extreme wet conditions in the 1988/1989 period, IC2 of Fig. 9 (i.e., Libya) indicated a drought condition in 1998 with recovery in 1999. As a result, Libya was more or less climatically stable (i.e., when compared to 1994, 2006, and 2012). While the conventional basin area was relatively wet during $2001-2014$ period (though with fluctuating SPI values) (IC1 of Fig. 9), drought conditions in the last decade (2001, 2009, and late 2013 - 2014) in Libya (IC2, Fig. 9) and southern Niger (IC4, Fig. 9) demonstrate the importance of a spatio-temporal approach to drought analyses. Apart from the SPI signal in Libya, recent wet conditions in 2010-2013 seems to be prevalent in the basin (IC1, IC3IC4, Fig. 9) with the conventional basin area indicating mostly wet conditions since 1999 (IC1, Fig. 9). The observed wet and dry periods from our localised drought signals, which we attribute partly to the impacts of La-Niña and El-Niño, respectively in the region are consistent with the findings of Nicholson et al. (2000) on the trends of rainfall conditions in West Africa. They identified 1988, 1994, and 1998 as the wettest years since the late 1960's (i.e., besides the pre-1980 period) while drier conditions prevailed in other areas of West Africa. In addition to these wet periods of 1988, 1994, and late 1998-2000 (IC1, Fig. 9), which are usually referred to as the rainfall recovery period in the Sahel (see, e.g., Nicholson, 2013; Nicholson et al., 2000), strong positive deviations in normal rainfall in 2012, which may be the combined influence of climate teleconnections (i.e., ENSO, AMM, and AMO as discussed further in the later part of the study) in the region are observed at all scales (see IC1-IC4, Figs. 7-9). Specifically, the 1998 and 1999 wet periods as observed in this study are consistent with the periods of high Chari flows, which led to flooding and loss of agricultural land within the southern basin (see Birkett, 2000). Moreover, for all monthly cumulations, we observed a relatively strong declining SPI values between 1980 and 1984 over the region (IC1-IC4, Figs. 7-9), which are consistent with well known and acknowledged extreme drought conditions of 1983-1984 in Africa (e.g., Masih et al., 2014). Likewise, a relatively stronger decline of SPI values are observed between 1980 and 1991/1992 mostly at Niger (i.e. IC3, Fig. 8) and Chad (i.e. IC3, Fig. 9). These extreme drought periods especially those occurring during 1982 - 1984 period (see e.g., IC1 and IC4 of Fig. 9) have been attributed to the synergy between the abnormally warm Indian Ocean SST and that of the eastern Atlantic, which suppressed rainfall in the Sahel due to large scale subsidence in the troposphere (see, e.g., Bader and Latif, 2011; Giannini et al., 2003). The Lake Chad basin had experienced prominent alterations in hydro-meteorological conditions in the past decades, which eventually led to widespread drought and sometimes flood in the 

were also observed in the extreme southern and northern part of the basin.
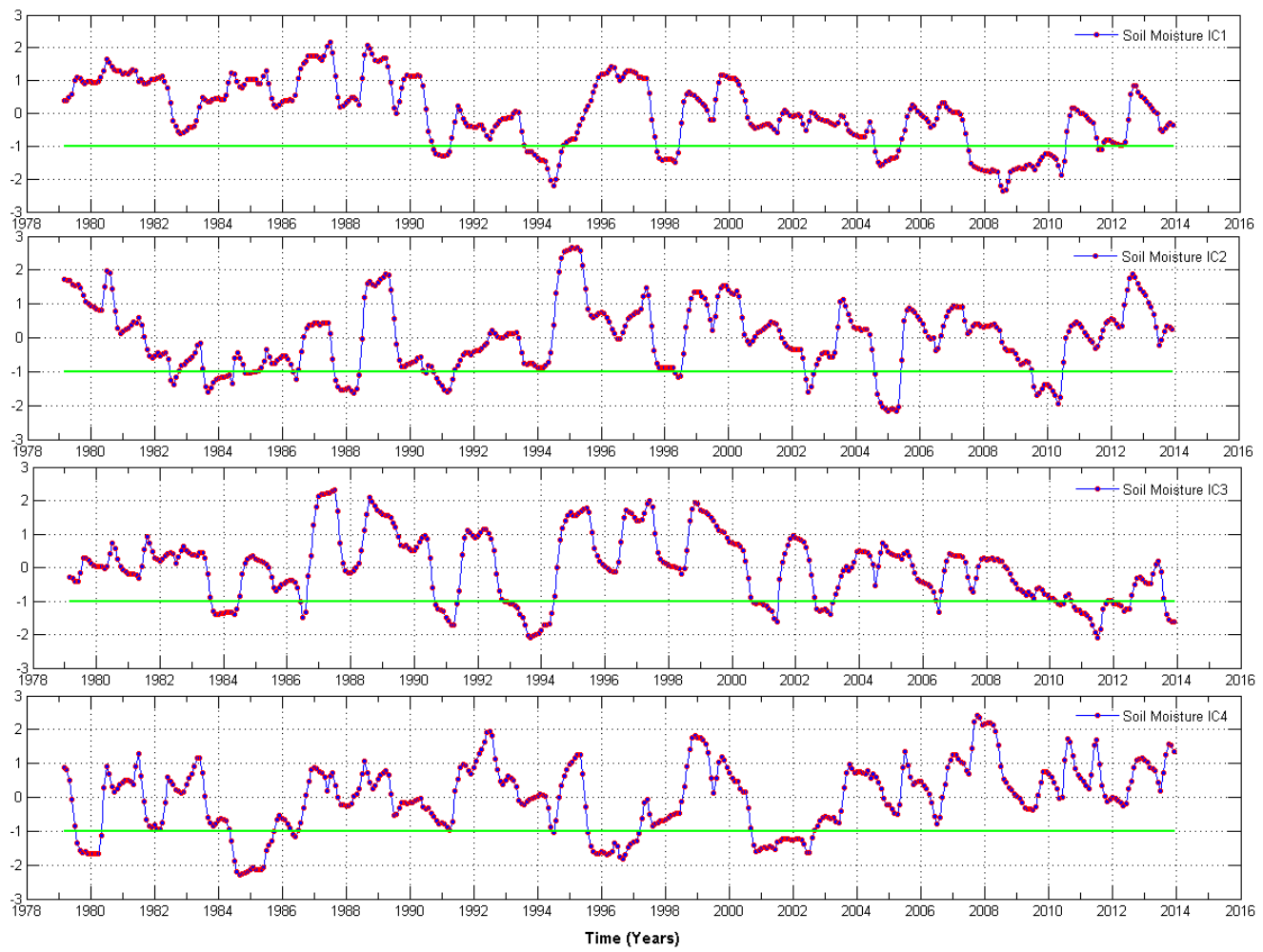
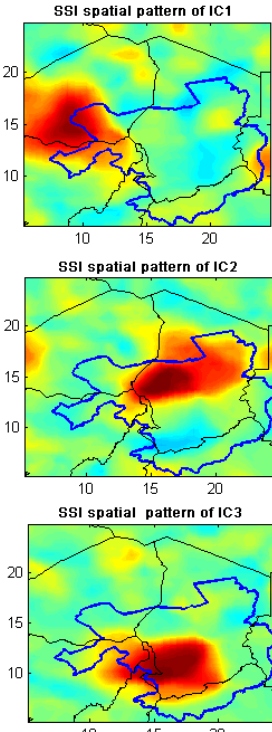

SSI spatial pattern of IC

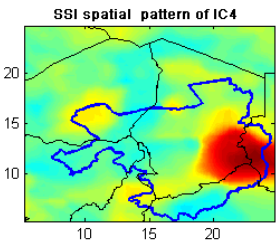

Figure 11: ICA-derived spatio-temporal SSI patterns of LCB using 3-month gridded SSI values. SSI values are computed using CPC model soil moisture product for the period 1979 - 2013. Localised spatial SSI patterns (right) corresponds to the temporal evolutions (left). The actual SSI values to be used for drought classification are jointly derived from the spatial and temporal SSI patterns. The green solid line is drought threshold.

Furthermore, we explored the relationship between SPI and global climate teleconnection indices that have been associated with rainfall variability and drought conditions in the Sahel. Results (Table 2) show that at 12 month SPI scale, AMO has a significant positive correlation of 0.55 with the first ICA mode of Fig. 9. In Fig. 10, we show the relationship of ICAdecomposed 12-month gridded SPI (i.e. IC1) with climate indices (i.e., AMO, ENSO, and AMM). We observe that the hydrological character vis-a-vis extreme rainfall conditions (e.g., droughts) of LCB could also be as a result of the influence of AMO. Our linear correlation result (Table 2) agrees with the findings of Diatta and Fink (2014), that pointed out the influence of AMO on rainfall conditions in the Sahel. They reported positive linear correlations $(0.28$ and 0.29) of AMO with West African Monsoon rainfall variability in two Sahel regions. Aligning with our perceived influence of AMO, Rodrguez-Fonseca et al. (2011) also reported on the impact of AMO on rainfall variability in the region. Still on the first independent mode of SPI 

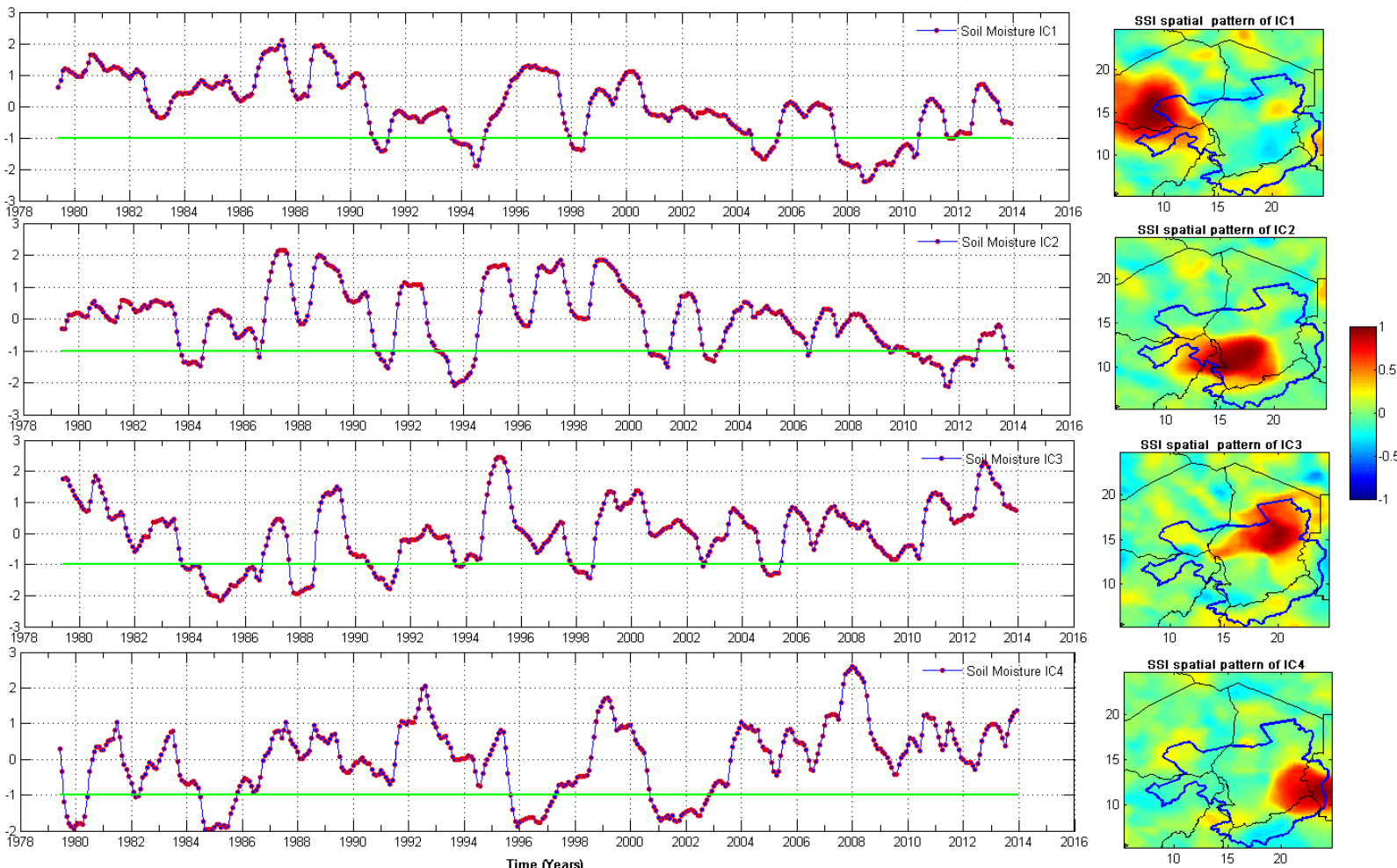

Figure 12: ICA-derived spatio-temporal SSI patterns of LCB using 6-month gridded SSI values. SSI values are computed using CPC model soil moisture product for the period 1979 - 2013. Localised spatial SSI patterns (right) corresponds to the temporal evolutions (left). The actual SSI values to be used for drought classification are jointly derived from the spatial and temporal SSI patterns. The green solid line is drought threshold. 


\subsubsection{Spatio-temporal Analysis of Drought Patterns for SSI}

Apart from precipitation, society usually depends upon usable water from various sources, such as soil moisture, streamflow, lakes, and reservoir storage for agriculture, ecosystem functioning, domestic, and industrial purposes. Consequently, most drought impacts can also be related to soil water drought (i.e., agricultural drought) and hydrological drought (abnormally low water levels, in lakes, reservoir levels, and groundwater). Previous drought studies have related hydrological and agricultural droughts with precipitation deficits on shorter and longer time scales such as 3, 6, 12, and 24 months cumulations (see, e.g., Li and Rodell, 2015; Lloyd-Hughes, 2012; Hayes et al., 1999; Komuscu, 1999). But the use of soil moisture in quantifying drought episodes that may be useful in hydrological applications and in understanding the propagation process of rainfall deficit to hydrological drought (i.e., through soil moisture deficit) are not known in the LCB. Hence, in order to investigate the spatio-temporal variability of agricultural and hydrological droughts, similar to the SPI concept of McKee et al. (1993), the CPC soil moisture product was used to derive the SSI. Results indicate that similar to the SPI (see Section 4.2.2), the 1983/1984 drought is captured here at all monthly scales in the basin (Figs. 11-13). Generally, while there seem not to be differences in drought frequency and persistence at all monthly scales, extreme wet years of 1988, 1994, 1998, and 2012 are consistent with results in Section 4.2.1. Apparently, at all monthly SSI accumulation scales, the central part of the conventional basin where the Lake is located (i.e., Lake Chad, Njamena and environs), show declining SSI values between 2008 and 2012, with extreme and severe drought conditions in 2011 and the early part of 2012, respectively (see IC3, Fig. 11 and IC2 of Figs. 12-13). Although the later part of 2012 in the central part of the conventional basin area shows drought recovery (e.g., IC2, Fig. 12), the inconsistency between the temporal evolutions of SSI and SPI in 2012 in this part of the basin is a contrasting hydrological situation that needs to be considered. This hydrological situation is attributed to a number of factors. First, in the previous years, drought persisted between 2010 and early 2012 with extreme drought condition observed in 2011 (see IC3, Fig. 11 and IC2 of Figs. 12-13), hence, the apparent soil moisture deficit even during periods of improved rainfall. Second, the rainfall must have been hyped-up due to its intensity in few months (e.g., July and August) while the remaining months of the year remained dry leading to observed drought condition. Third, it could be that the strong amplitude of rainfall in 2012 (see Fig. 4) and the wet conditions observed from the spatio-temporal analysis of SPI (Figs. 7-9) was not significant enough to be reflected in soil water storage. Another argument in this regard could be that the previous 

inconsistencies between SPI and SSI signals. Moreover, model soil moisture products driven
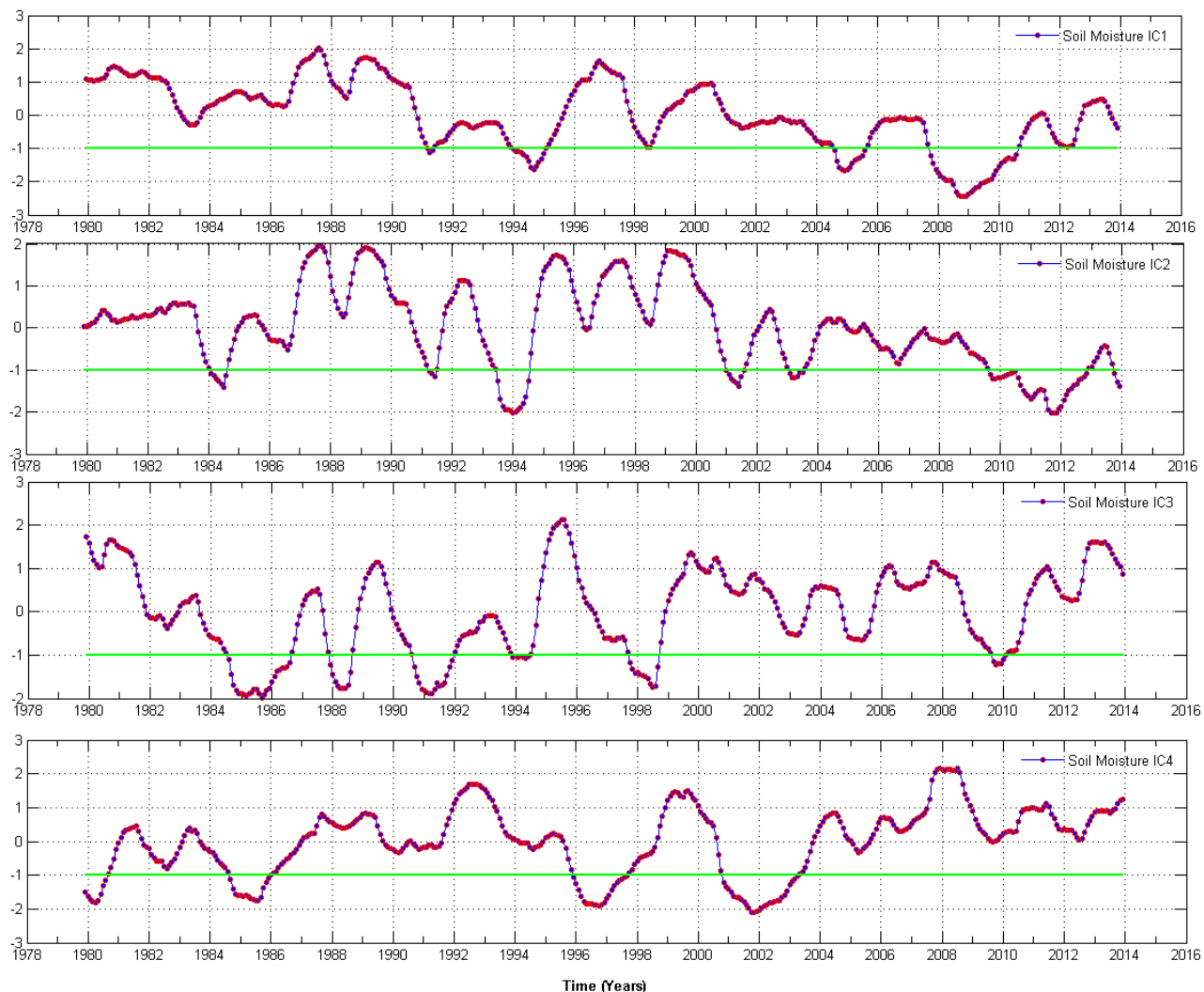
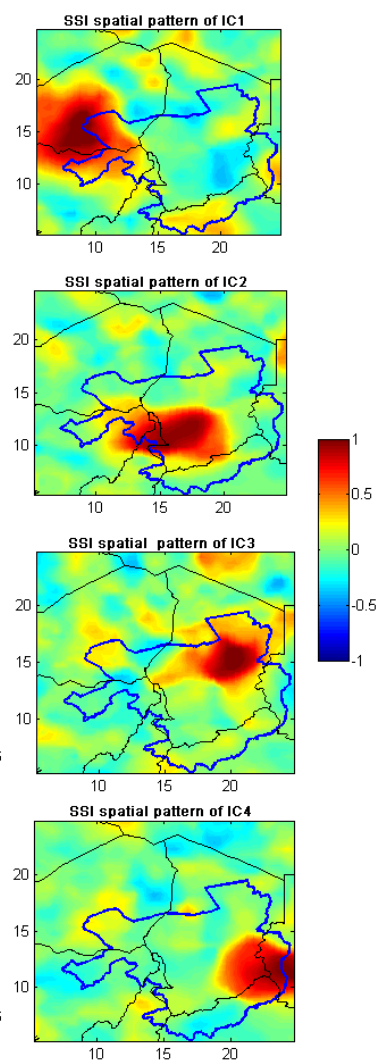

Figure 13: ICA-derived spatio-temporal SSI patterns of LCB using 12-month gridded SSI values. SSI values are computed using CPC model soil moisture product for the period 1979-2013. Localised spatial SSI patterns (right) corresponds to the temporal evolutions (left). The actual SSI values to be used for drought classification are jointly derived from the spatial and temporal SSI patterns. The green solid line is drought threshold.

by observed meteorological forcing may show some limitations. They are inconsistent during extreme wet and dry conditions and tend to show limited skills in regions with strong annual rainfall cycle (Dirmeyer et al., 2004). Nevertheless, consistent with our arguments, Dirmeyer et al. (2004) indicated that the variability in model soil moisture products may not completely follow the variability in rainfall as a result of the surface characteristics of the soil.

In other drought events of the basin, extreme drought condition is observed on the southeast 
part of the conventional basin during the periods of $1984-1985,1996-1997$, and $2000-2003$ (IC4, Figs. 11-13). Also, this period (2000 - 2003) shows one of the period with the longest drought duration (i.e., soil moisture deficit, IC4 of Figs. 11-13) in the study and is consistent with the observed well pronounced negative water levels shown in Section 4.3. Note that this southeastern part of the conventional basin is also made up of tributaries that flows into the Chari-Logone river system. Hence, the observed extreme drought for the periods of 1984-1985, 1996-1997, and 2000-2003 as indicated in IC4 of Figs. 11-13 are specific examples of severe water shortage with grave agricultural and domestic consequence in the Lake and the conventional basin. Further, longer drought duration in recent times, is observed in the part of the basin that belongs to Niger between 2008 and early part of 2010 (see IC1, Figs. 11-13). This generally leads us to the understanding that the hydrological footprint of LCB in recent times (e.g., 2008 - 2012), indicates reduced alimentation and water deficit. It is likely that the loss of soil water storage in the basin could be the result of huge evapotranspiration and insufficient rainfall during the previous years. Although other environmental conditions such as increased surface temperature in the basin may intensify the soil moisture deficit conditions, SPI temporal evolutions (i.e., at 3 and 6 months aggregation) showed drought conditions in 2009, 2011, and early 2012 (IC1 of Figs. 7 and 8), coinciding with the soil moisture deficits during 2009 - 2012 period (IC3 of Fig. 11 and IC2 of Figs. 12 and 13). To further consolidate on these findings, the results of TWS regionalisation is presented in the next section.

\subsection{Dynamics in Land Water Storage over the Lake Chad Basin}

From the statistical decomposition of TWS changes over the LCB, four significant modes of variability were identified. The ICA approach generally, shows a relatively better performance in exploring the spatial dynamics of variability in GRACE-derived TWS changes compared to PCA, which was recently employed in analysing TWS and rainfall over West Africa by Ndehedehe et al. (2016a). The four modes of TWS variability (IC1-IC4, Fig. 14) analysed indicate a total variability of $67.6 \%$ with the first mode explaining $27.6 \%$ variability while IC2, IC3, and IC4 explained 16.2\%, 13.6\%, and 10.2\%, respectively. IC1 (Fig. 14) is a strong hydrological signal emanating from the Benue river drainage basin (i.e., north-east Nigeria, as can be seen in the corresponding spatial pattern), which is made up of freshwater tributaries that also flows into LCB (cf. Fig. 1, left ). This signal is mostly outside the conventional basin area but surface waters (i.e., rivers) from north-east Nigeria also provides nourishment to the LCB. From the temporal patterns (IC1, Fig. 14), a statistically significant increase of $12 \pm 4.0$ 

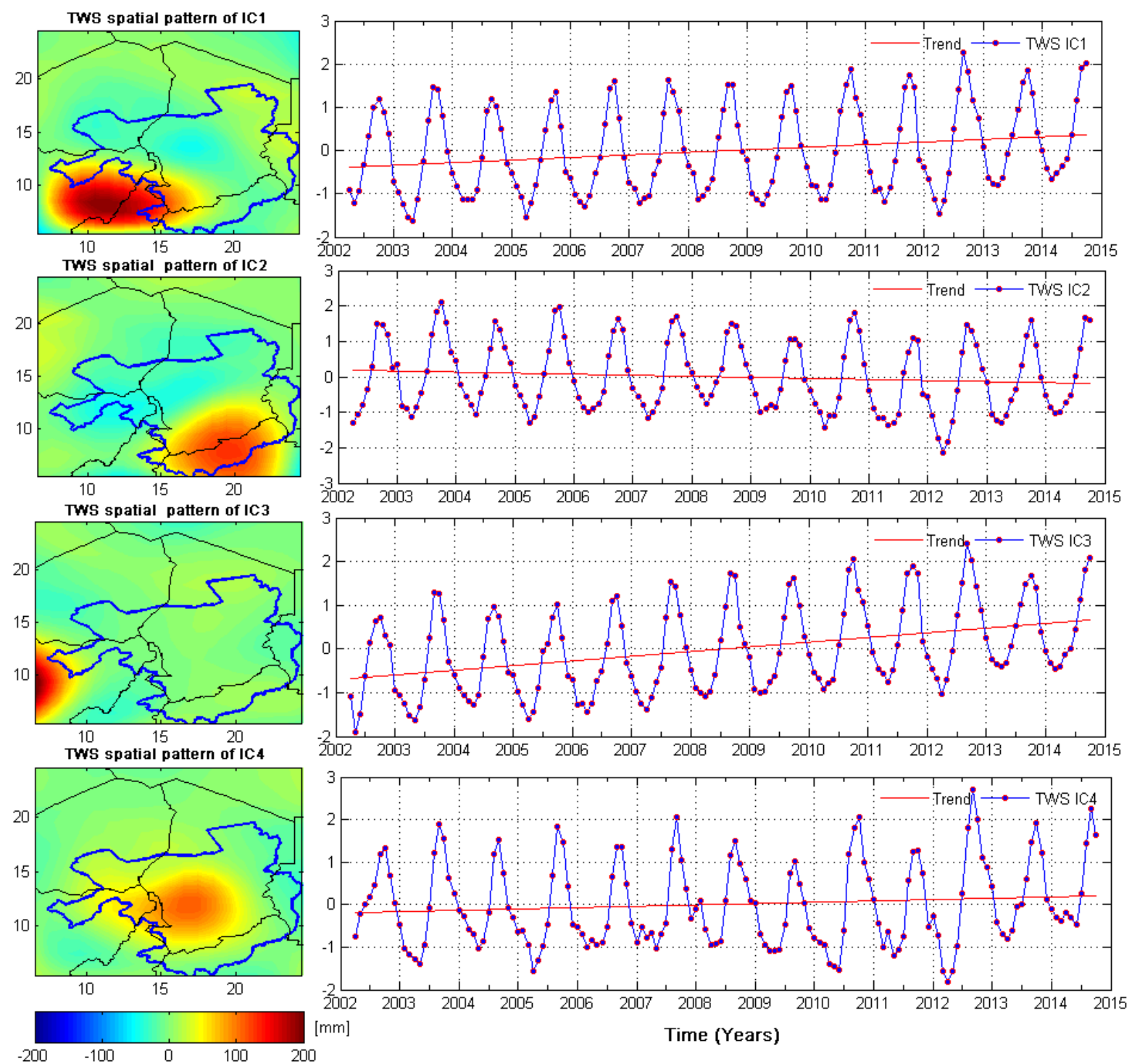

Figure 14: The independent components (right) of GRACE-derived TWS $(2002-2014)$ over LCB corresponding to spatial patterns (left), which are scaled using the standard deviation of the computed independent components. These independent components are unitless since they have been standardised using their standard deviations.

$\mathrm{mm} / \mathrm{yr}$ between 2002 and 2014, which is attributed to rainfall is observed. IC2 (Fig. 14) is TWS variability in the southern sector of the basin where $~ 95 \%$ of LCB's nourishment takes its origin. It is basically the TWS change in the southern catchment of the basin where average monthly rainfall between July and September could be up to $300 \mathrm{~mm}$ (cf. Fig. 5, left). TWS in this southern catchment indicates a statistically insignificant decline of $4.5 \mathrm{~mm} / \mathrm{yr}$ (IC2, Fig. 14). This decline may be the result of marked fluctuations in precipitation patterns as the SPI indicates frequent drought conditions with relatively short durations during the 2002-2014 period (IC2 and IC4 of Figs. 7 and 8). IC3 (Fig. 14) is the hydrological signal from Nigeria, 
the Kainji reservoir area to be specific. The statistically significant increase of $22 \pm 4.0 \mathrm{~mm} / \mathrm{yr}$ can be attributed to water ponding in the Kainji reservoir and probably increase in rainfall within the period. Lastly, the statistically insignificant increase of $3.0 \mathrm{~mm} / \mathrm{yr}$ in the central part of the conventional basin area, as observed in IC4 (Fig. 14), coincides with the water deficit conditions discussed in Section 4.2.3.

The hydrological condition of the LCB has not been a one-sided narrative of desiccation and decline in surface water extent as two inter-decadal wet/dry cycles have been observed in the altimetry time series (Fig. 15). Essentially, the cumulative rainfall anomalies in Fig. 3 and the increase of $0.04 \pm 0.03 \mathrm{~m} / \mathrm{yr}$ (statistically significant at $95 \%$ confidence level) in the satellite altimetry derived water levels of Lake Chad during the 2008 - 2014 period (see, Fig. 15) suggest wetter conditions given the endemic droughts that ravaged the basin in the past. Such circumstance (increased altimetry water levels of Lake Chad or wet conditions around the Lake area), which occasionally leads to flood in the basin can also be attributed to high flows from the Chari river catchment, a major source of the Lake's nourishment. During such periods (i.e., high flow) as noted by Coe and Birkett (2004), the marshlands and areas around the shores of Lake Chad get flooded and may lead to crop damage while the dry years lead to reduced yields in both fishing and farming. Such fluctuating hydrological conditions are largely caused by extreme rainfall conditions and can be seen in the Lake's temporal and spatial patterns (see Fig. 2). For instance, in 1987 when the SPI time series over the basin all indicated severe and extreme drought conditions at all monthly aggregations (see Fig. 6a-d and Figs. 7-9), the northern pool completely disappeared leaving behind debris and dunes (Fig. 2, right). Further, Lemoalle et al. (2012) reported the occasional flooding and drying of the Lake (mostly the northern pool) and associated them with inter-annual rainfall conditions in the basin (especially the southern part of the basin). The satellite image analysis of Lake Chad in recent decade indicates a loss of about $573 \mathrm{~km}^{2}$ in surface area between 2000 and 2015 while an estimated loss of $249 \mathrm{~km}^{2}$ between 2000 and 2003 was observed. Using NOAA's Advanced Very High Resolution Radiometer (AVHRR) images, Birkett (2000) estimated the Lake's areal extent as $1,385 \pm 25 \mathrm{~km}^{2}$ in 2000 while Coe and Foley (2001) reported an area less than $1,350 \mathrm{~km}^{2}$ in 2001 as the active area of the Lake. This further emphasizes the continuous shrinking of the Lake even during a relatively short period of time. Our surface area estimation of the Lake in those years (i.e., $2000\left(\sim 1576 \mathrm{~km}^{2}\right), 2003\left(\sim 1326 \mathrm{~km}^{2}\right)$, and $\left.2015\left(\sim 1003 \mathrm{~km}^{2}\right)\right)$ was treated cautiously as they only followed the outline of the southern pool (cf. Fig. 2). There are indications that the lake is still receding though with possibilities 

(i.e., Coe and Foley, 2001) concluded that the Lake had completely disappeared.

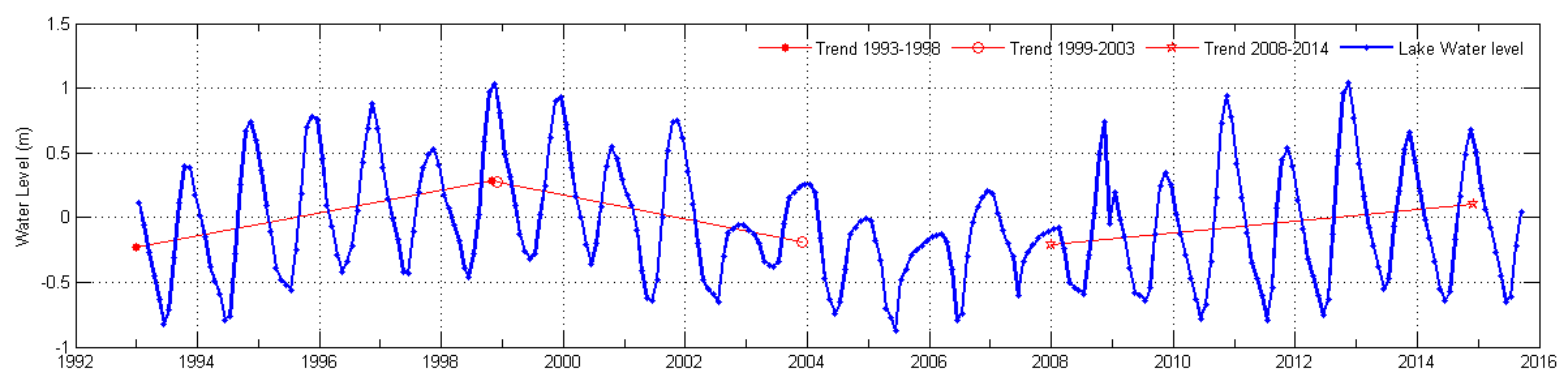

Figure 15: Trends in Lake Chad water level variation derived from satellite altimetry data for the period 1993-2015. pool is partially inundated with Chari river discharge falling between 470 and $1080 \mathrm{~m}^{3} / \mathrm{s}$ (see, Lemoalle et al., 2012). Given the rising trend in cumulative rainfall anomalies during the $2012-2014$ period (Fig. 3a) and trends in lake water level (Fig. 15), the likelihood of such possibilities in recent times $(2008-2014)$ is apparent. However, the observed insignificant trends in TWS of the Lake Chad area (IC2 and IC4 of Fig. 14) and the soil moisture deficit conditions (see Section 4.2.3) make us to be cautiously optimistic about such tendencies. This is because soil moisture deficit decreases recharge to groundwater, leading to groundwater deficit and severe hydrological drought (Loon, 2015). But given that the Lake surface extent and inundation areas are related to wet periods in the basin, the rising trend in cumulative annual rainfall anomalies (Fig. $3 \mathrm{~b}$ ) and the wet periods observed in the conventional basin area (see Section 4.2) may be deviations in the hydro-meteorological patterns of the region that could improve agriculture and strengthen socio-economic activities within the basin. Notably, the slow desiccation of the Lake has been largely perceived as the combined effect of changes in regional precipitation patterns and anthropogenic influence (e.g., Birkett, 2000; Coe and Foley, 2001). The improved rainfall conditions in recent times as observed in the SPI and cumulative rainfall anomalies, could be a simple return to near-normal hydrological conditions in the Lake Chad area. As indicated in Fig. 3, the recent rainfall trends over the basin, which is also apparent in the recent (2008 - 2014) altimetry time series (Fig. 15) over the Lake, may reverse the drought narrative of the basin. This assumption may imply a possible resurgence of the normal Lake, in the absence of any further severe marked alteration of the current hydro-meteorological patterns of the basin. This position contrasts with the perceptions of Moore and Williams (2014) regarding the present Lake Chad, who based on an earlier report

of reverting back to the Small Lake Chad during increased rainfall, a period when the northern 


\subsection{Lake Chad Water Resources: Synopsis and Policy Options}

The desiccation and decline in the surface area of Lake Chad has been largely attributed to impacts of climate variability and human activities (see, e.g., Coe and Foley, 2001; Birkett, 2000). As highlighted previously in Section 1, Lake Chad receives it nourishment from 95\% of discharge from the Chari/Logone river network in the southern part of the basin and $\sim 2.5 \%$ of discharge from the Komadougou-Yobe river system in Nigeria. According to Coe and Birkett (2004), the Chari/Logone river discharge, which is measured at N'Djamena (see Fig. 1) and the discharge from Komadougou-Yobe river system and precipitation over the lake surface are balanced by seepage to groundwater, evaporation, and inter-annual storage. Considering the importance of the two river systems that nourishes Lake Chad, the inter-annual variations of water storage from these two drainage systems can be used to predict and determine water storage changes in the Lake. Let us recall that IC2 and IC4 of Fig. 14 are TWS signals from the Chari/Logone river system. Observed TWS trend in the Chari/Logone drainage system indicates a decline of $4.5 \pm 3.0 \mathrm{~mm} / \mathrm{yr}$ and an increase of $3.0 \pm 2.0 \mathrm{~mm} / \mathrm{yr}$ for IC2 and IC4 of Fig. 14, respectively. Also within the Chari/Logone drainage system (see IC3, Fig. 11 and IC2, Figs. 12 and 13), soil moisture deficit and hydrological drought (i.e., at 3, 6, 12 month scales) have been observed between 2010 and 2012. Given these hydrological situations in the LCB, one may assume that the potential for further desiccation and reduced alimentation are likely in the years to come. In a recent study, Greve et al. (2014) observed that the Sahel region (i.e., region where the basin is located) is actually leaning towards aridity. The dry gets dryer paradigm as observed in the study (Greve et al., 2014), was largely attributed to significant drying trends in water availability and changes in large-scale circulation patterns.

Further, when trends in the variations of Lake Chad water levels are considered, the increase of $0.09 \pm 0.03 \mathrm{~m} / \mathrm{yr}$ and $0.04 \pm 0.03 \mathrm{~m} / \mathrm{yr}$ in $1993-1998$ and $2008-2014$, respectively might be insignificant when compared to the decline of $0.09 \pm 0.03 \mathrm{~m} / \mathrm{yr}$ in $1999-2003$ (Fig. 15). This is because the hibernation period in the Lake (2002 - 2007, Fig. 15) where a great deal of less pronounced annual amplitudes in water levels are observed may rescind the effect of the previous increase in the Lake's height $(1993$ - 1998), leading to a hypothetical water deficit (especially with the human disturbance of the Lake). We make this assumption because the impact of extreme drought conditions of previous years are known to have negative effects on surface waters even after an improved rainfall condition in the present (see, e.g., Bekoe and Logah, 2013). For example, the relatively strong and consistent negative anomalies, observed in water levels all through the period between 2004 and 2005 coincides with observed extreme 
drought conditions in the conventional basin area within the same period (see, IC4 of Fig. 9; IC1-IC2 of Fig. 11; IC1 and IC3 of Fig. 12 and ; IC1 of Fig. 13). In the same vein, the increase of $\sim 0.04 \mathrm{~m} / \mathrm{yr}$ between 2008 and 2014, when related to the current surface extent of the Lake, which stands at $\sim 1002 \mathrm{~km}^{2}$ gives an increase of $\sim 0.04 \mathrm{~km}^{3} / \mathrm{yr}$ of water in the Lake. This amount of water is relatively small when compared to $33 \mathrm{~km}^{3} / \mathrm{yr}$ of water that flowed from the Central African Republic to the LCB in the 1970's and $\sim 17 \mathrm{~km}^{3} / \mathrm{yr}$ in the 1980's (FAO, 1997). This comparison could be useful in assessing lake water level trends and the impact of climate variability and human influence on the Lake. Moreover, dam construction and increasing irrigation activities in the 1980's contributed a great deal to the desiccation of Lake Chad, putting the water requirements of the basin at $12.525 \mathrm{~km}^{3} / \mathrm{yr}(\mathrm{FAO}, 1997)$. If human activities in the basin intensify, the resurgence of the Lake may be far away than expected, given that about $21 \mathrm{~km}^{3} / \mathrm{yr}$ of water is expected to permanently maintain the Normal Lake Chad as it was in the 1960's (Lemoalle et al., 2012). Going by the observed trends in TWS changes (see Section 4.3), much of the conventional basin, which is under the mandate of Lake Chad Basin commission, is somewhat stable in terms of freshwater availability. Although soil moisture indicated deficit (see Section 4.2.3) during 2009 - 2013 period, in the event that the observed improved rainfall conditions (Section 4.2.2) of the basin persist, the hydrological condition may be altered significantly, leading to freshwater availability. We acknowledge the limitation of our study owing to the lack of in-situ river discharge data, especially for the Chari river system. However, the observed trends in TWS changes and altimetry-derived water levels, which depends largely on the river flow from the Chari river system, provides us with a clue regarding recent hydrologic conditions of the Chari river system. This is particularly true because, Coe and Birkett (2004) demonstrated the possibility of using radar altimetry to predict discharge at N'Djamena and the Lake stage within the permanent waters of the Lake bed (i.e., the Lake Chad).

Lake Chad, which is shared by four riparian countries (Nigeria, Chad, Cameroon, and Central African Republic) has suffered huge desiccation and decline in the last three decades due to decrease in rainfall and extreme hydrological drought conditions. But the corresponding basin has been a hub of huge loss of bio-diversity and extreme climate conditions with severe consequences on freshwater availability. In addition, large irrigation schemes and other forms of human activities (e.g., Lemoalle et al., 2012; Coe and Foley, 2001) also profoundly contributed to the much pressure on the basin's water resources, leading to freshwater deficit. These resulted in the hypothetical decision of transferring water from the Congo basin to 
support the LCB (see, e.g.,.., Lemoalle et al., 2012; Inogwabini et al., 2006). While the use of legislation to ensure sustainable practices and long-term conservation of the basin's water resources is essential, we suggest that the ground water resources and aquifer storage be investigated. This can be achieved in future studies by using scientific methods such as the combination of GRACE observations, in-situ data, and outputs from hydrological models. Seepages, infiltration, evapotranspiration, and the effect of the Lake on local recycling of precipitation will have to be fully understood in order to address the challenging physical, and hydrological conditions of the basin. Our approach in drought monitoring and TWS analysis can be employed in inter-basin water transfer projects. For instance, understanding the space-time evolutions of extreme rainfall conditions and changes in TWS of the Congo basin could be useful in managing a hypothetical water transfer to the LCB. This will complement technological, institutional, and other policy solutions in water resources planning. While it is important to investigate the ground water resources of the basin using robust scientific methods as proposed, our contribution provides a general framework for drought monitoring and the understanding of changes in TWS of the region and other parts of the world. For the LCB, the findings of this study can assist and support improved legislation and policies tailored towards the regulation of unsustainable practices. Furthermore, as outlined in Vassolo (2012), few steps have been taken by the Lake Chad Basin commission to strengthen the trans-boundary water resources of the region. They include (i) the adoption of United Nations draft resolutions for trans-boundary aquifers as a basic document that will support groundwater management and (ii) the planned adoption of a Water Charter for the basin to enable the regulation of shared management of water resources and ecosystems. As indicated in the groundwater need assessment of Vassolo (2012), trans-boundary surface water has not been extensively studied since the establishment of the Lake Chad Basin Commission, leading to poor understanding of the trans-boundary groundwater resources. Hence, multi-satellites, especially satellite gravimetric approaches using GRACE observations and outputs from hydrological models can be adopted to monitor the groundwater resources of the basin in future studies.

\section{Conclusions}

In this study, we used independent component analysis (ICA), a fourth-order cumulant statistics to characterise and localise space-time evolutions of drought patterns over the LCB. Satellite altimetry data was employed to analyse Lake Chad water level variations while nor- 
malised time series of climate teleconnection indices were used to examine the association of SPI temporal evolutions with coupled atmosphere-ocean system. In addition to the drought signature that have been identified, the LCB has also been used primarily as a tentative test bed to demonstrate the spatio-temporal variability of drought. Also, trends and spatial variability of TWS changes in LCB were investigated. The results in this study are summarised as follows:

1. We observed some unusual deviation from the long string of drought conditions observed in the basin as the time series of SPI values between late 2010 and early 2013 are indicative of wet conditions. These wet conditions are attributed to recent increase in rainfall over the basin and is also consistent with recent increase in Lake Chad water levels. However, from the spatio-temporal drought analysis and trends in TWS changes the southern part of the basin, which provides $\sim 95 \%$ of the total input to the basin's surface water indicates a deficit, as the SSI between late 2009 and 2012 shows drought conditions at 6 and 12 month cumulations.

2. The time series of SSI and MSDI are inconsistent with extreme positive SPI values (wet conditions) at 12 month aggregation as they both indicate extreme drought conditions and in some cases near-normal conditions. For the SSI, this may be the effect of previous drought conditions, high evaporation due to low humidity and high temperatures, and seepage to groundwater amongst others.

3. Drought analysis with SPI shows that drought persistence is higher on a longer time scale while on short time scales drought becomes more frequent. Generally, while there seem not to be differences in drought frequency and persistence at all monthly scales for SSI spatiotemporal analysis, extreme wet years as identified in the study (e.g., 1988, 1994, and 1998) are consistent with results of spatio-temporal drought analysis for SPI.

4. Apart from the droughts of the 1980's, the spatio-temporal analysis of SPI at 3 and 6 month scales indicated fluctuating drought conditions with relatively short duration in the last two decades in the extreme southern part of the basin. These drought conditions coincide with the observed decline in TWS (though statistically insignificant at 95\% confidence level) around the precinct of the southern part of the basin. On the contrary, the trend in TWS changes during the $2002-2014$ period shows an insignificant increase at the center of the basin, coinciding with soil moisture deficit indicated by the temporal evolutions of SSI at all monthly accumulations during the $2002-2003$ and 2009 - 2012 periods. It is unclear if this could be a temporary soil water shortage condition due to surface and hydraulic characteristics of the soil, seepages or increased evapotranspiration and surface temperature over the basin. 
This can be clarified further in future studies by integrating GRACE-derived TWS and other soil moisture data to investigate the groundwater resources of the basin. Overall, the ICA approach to drought analysis demonstrates the spatio-temporal variability of drought, which largely may depend on the local climatic or meteorological conditions.

5. Also, while the ICA method shows a common hydrological drought period, which lasted for about two years (i.e., 1982 - 1984) in the basin, other areas within the conventional basin have been affected by both agricultural and hydrological droughts at different time periods.

6. Apart from the negative correlation of ENSO with 12 month SPI, our results show that at 12 month SPI scale, AMO and AMM have statistically significant positive correlations of 0.55 and 0.38 , respectively with the first ICA mode of Fig. 9. This indicates that the hydrological character in relation to extreme rainfall conditions (e.g., droughts) in LCB could also be influenced by these climate teleconnection modes.

7. In addition to improved rainfall conditions during 2010 and early 2013 period, two interdecadal wet/dry cycles have been observed in the altimetry time series. Generally, our SPI, satellite altimetry, and TWS results within the precincts of the conventional basin indicate relatively wet conditions in the last decade as opposed to soil moisture deficits around the vicinity of the Lake. Our contribution provides a framework for drought monitoring that can assist and support management decisions, legislation, and policies tailored towards water resources and agriculture. 


\section{Appendix A1: Seasonal Rainfall Variability using the GPCP-based Precipitation}
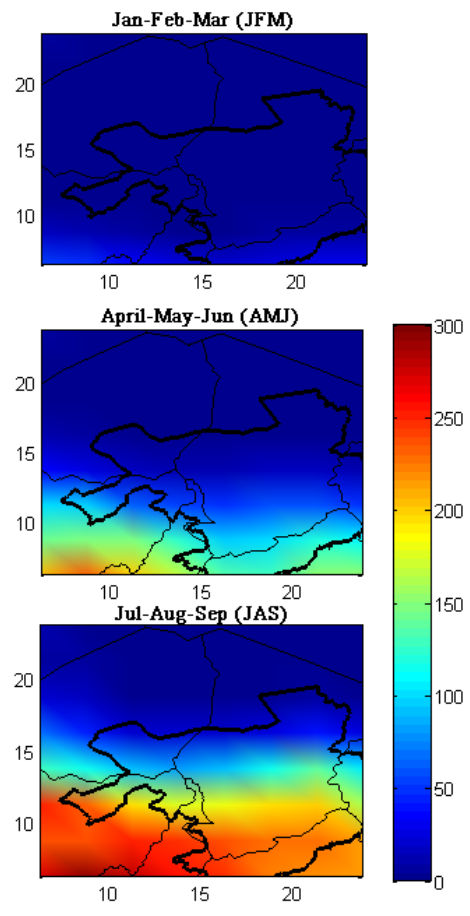

Oct-Nov-Dec (OND)

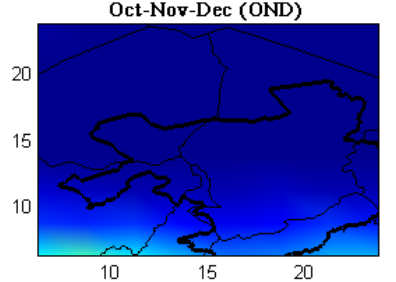

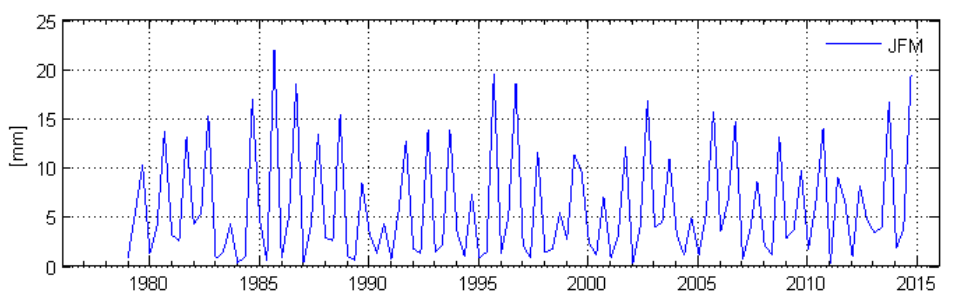
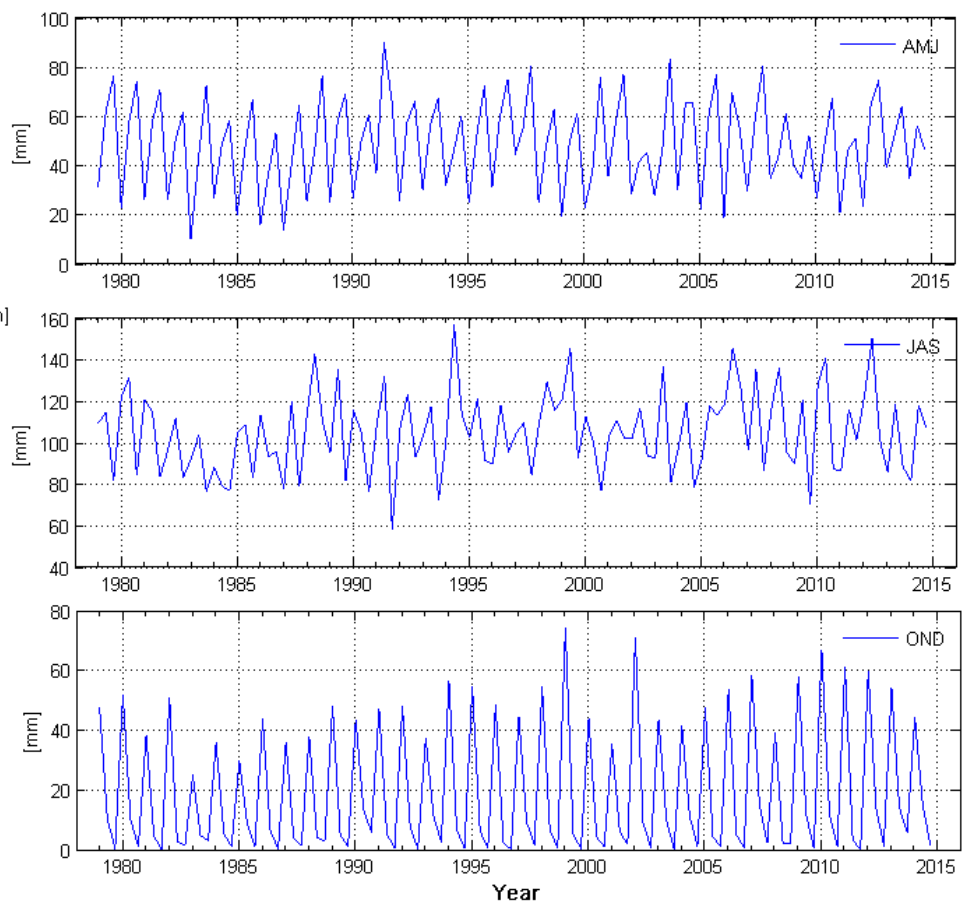

Figure 16: Seasonal rainfall analysis for Lake Chad Basin $\left(5.5^{\circ} \mathrm{N}-24.5^{\circ} \mathrm{N}\right.$ and $\left.5.5^{\circ} \mathrm{E}-24.5^{\circ} \mathrm{E}\right)$ using GPCP based precipitation for the period 1979-2014. Spatial patterns (left) and temporal patterns (right) are averaged over the geographical boundary describing the spatial extent of Lake Chad basin used in this study. The insert (i.e., the solid black line) is the conventional basin boundary. 


\section{Appendix A2: Further description of the ICA Technique}

ICA is a higher order statistical technique that decomposes multivariate data into statistically independent signals (see, e.g., Cardoso and Souloumiac, 1993; Cardoso, 1999). The method, which is usually referred to as blind source separation in signal processing (e.g., Cardoso, 1999), explores the unknown dynamics of a system through the rotation of the classical empirical orthogonal functions (Aires et al., 2002). ICA has emerged as a better alternative to principal component analysis (PCA, e.g., Jolliffe, 2002), an extraction method that is used to reduce the dimension of large multivariate data. Though mathematically simple and a useful tool in terms of information compression, however, the capability of PCA to extract individual modes of variability that are physically meaningful is limited, hence the quest for higher order statistical method such as the ICA. In our case, the strong spatial variability of rainfall in the Sahel region at annual scale constrains the effectiveness of SPI in drought analysis. Hence, decomposing SPI time series using ICA will localise the space-time drought patterns in the region. Localising SPI and SSI signals in LCB will provide a better understanding as to the drivers of hydro-climatic variability in the region. To this end, as a first step in our analysis, the PCA method, was employed to identify statistically significant dominant modes of variability in the data (i.e the computed gridded SPI and SSI values and GRACE-derived TWS). The significant PCA modes (i.e., a combination of the principal components and empirical orthogonal functions) were identified as

$$
\mathbf{P}_{i}=\mathbf{e}_{i j} \mathbf{x}_{j}
$$

where $\mathbf{P}_{i}$ are linear combinations of $\mathbf{x}$ and $\mathbf{e}_{i j}$ are the set of empirical orthogonal functions (EOFs). Projecting the data $\mathbf{x}$ onto the EOFs we obtain the principal components (PCs) $\mathbf{P}_{i}$, which can be expressed as

$$
\begin{gathered}
P_{i, 1}=e_{11} \mathbf{x}_{1}+e_{12} \mathbf{x}_{2}+e_{13} \mathbf{x}_{3}+\ldots+e_{1 k} \mathbf{x}_{i, k} \\
P_{i, 2}=e_{21} \mathbf{x}_{1}+e_{22} \mathbf{x}_{2}+e_{23} \mathbf{x}_{3}+\ldots+e_{2 k} \mathbf{x}_{i, k} \\
\ldots \\
P_{i, k}=e_{k 1} \mathbf{x}_{1}+e_{k 2} \mathbf{x}_{2}+e_{k 3} \mathbf{x}_{3}+\ldots+e_{k k} \mathbf{x}_{i, k}
\end{gathered}
$$

$\mathbf{e}_{i j}$ is determined such that $P_{i, 1}$ are the new uncorrelated variables and the expression of the original data in the new coordinate system. $P_{i, 1}$ explains the highest variance of the multivariate data $\mathbf{x}$ while $P_{i, 2}$ up to $P_{i, k}$ explain the possible amount of the remaining variance. The EOF's are spatially orthonormal while the PC's are orthogonal and linearly independent. 
The next step was to rotate these dominant patterns (i.e., the statistically significant modes), which are uncorrelated towards statistical independence using the Joint Approximate Diagonalisation of Eigen matrices (JADE) algorithm described in Cardoso and Souloumiac (1993). The JADE approach exploits the fourth order cumulants of the data matrix rather than the moments (Cardoso, 1999). The cumulants are formed through the PCA process and diagonalised in order to find a rotation matrix that solves the optimization problem (Cardoso and Souloumiac, 1993). ICA decomposes the time series of data matrix $x_{i}(t)$, which consist of a mixing matrix $A$ and a number of statistically independent source signals $s_{j}(t)$ where $t$ is the time index. This can be expressed as (Ziehe, 2005)

$$
x_{i}(t)=\sum A_{i j} s_{j}(t), \quad(i=1, \ldots, n, \quad j=1, \ldots, m)
$$

$x_{i}$ in Eq. 9 is the mixing model and can be represented as a matrix as

$$
\mathbf{X}=\mathbf{A S}
$$

where the entries of the data matrix $\mathbf{X}$ are samples of the $x_{i}(t)$ given in Eq. 9, the $n \times m$ matrix $\mathbf{A}$ has elements $A_{i, j}$ and $\mathbf{S}$, the source signals. Essentially, ICA aims at recovering the set of source signals $\mathbf{S}$ completely from the observed data matrix or the mixed signal $\mathbf{X}$, by estimating either the mixing matrix $\mathbf{A}$ or its inverse $\mathbf{A}_{T}=\mathbf{A}^{-1}$. Overall, the ICA problem consist in factoring (i.e solving the optimisation problem) the observed signals in data matrix $\mathbf{X}$ into the mixing matrix $\mathbf{A}$ and the source signals matrix $\mathbf{S}$. The factoring problem is not uniquely determined and as such many solutions exist that solves the problem (see Ziehe, 2005). Most ICA methods are based on maximum-likelihood estimation, maximization of the output entropy or minimization of mutual information between the outputs, which is equivalent to the minimization of the Kullback-Leibler divergence between the joint and the product of the marginal distributions of the outputs (see more details in Ziehe, 2005). However, on grounds of numerical and computational efficiency, our approach uses the joint diagonilisation of the fourth order cumulant matrices (see, Cardoso and Souloumiac, 1993). The cumulantbased method exploits the remote properties of the signals, which include non-Gaussianity, non-stationarity, and spectral non-Flatness (e.g., Ziehe, 2005). Cumulants are empirically computed from higher-order moments, which are estimated from the data. From the Joint Approximate Diagonalisation of Eigen matrices (JADE) approach (Cardoso, 1999; Cardoso and Souloumiac, 1993), this fourth-order cumulant tensor provides the suitable matrices to be 
diagonalized, which are non-gaussian (see, e.g., Cardoso, 1999; Ziehe, 2005):

$$
\mathbf{C}_{i, j}(\mathbf{M})=\sum \operatorname{cum}\left(x_{i}, x_{j}, x_{u}, x_{v}\right) \mathbf{M}_{u, v},
$$

such that $\mathbf{M}$ is an arbitrary matrix. After the eigen decomposition of the centered covariance matrix $x$, which is aimed at reducing the dimension of the original data, the JADE algorithm performs an approximate joint diagonalisation of the set of eigen matrices of the cumulant tensor with an orthogonal transformation, which comprises a sequence of plane rotations (see, e.g., Ziehe, 2005; Cardoso and Souloumiac, 1993). This cumulant-based methods have been exhaustively described in the pioneering works of Cardoso and Souloumiac (1993), Common (1994), and Cardoso (1999). For further details on numerical steps and mathematical formulations, we refer interested readers to relevant literatures on the subject (see, e.g., Forootan and Kusche, 2012; Theis et al., 2005; Ziehe, 2005; Cardoso and Souloumiac, 1993; Cardoso, 1991; Common, 1994; Cardoso, 1999). While ICA has been previously used to filter and analyze the hydrological signals in GRACE data (see, e.g., Boergens et al., 2014; Forootan and Kusche, 2012; Frappart et al., 2010, 2011), the current study employed ICA for the statistical decomposition of SPI, SSI, and TWS signals over the Lake Chad basin. 


\section{Lake Chad Basin}
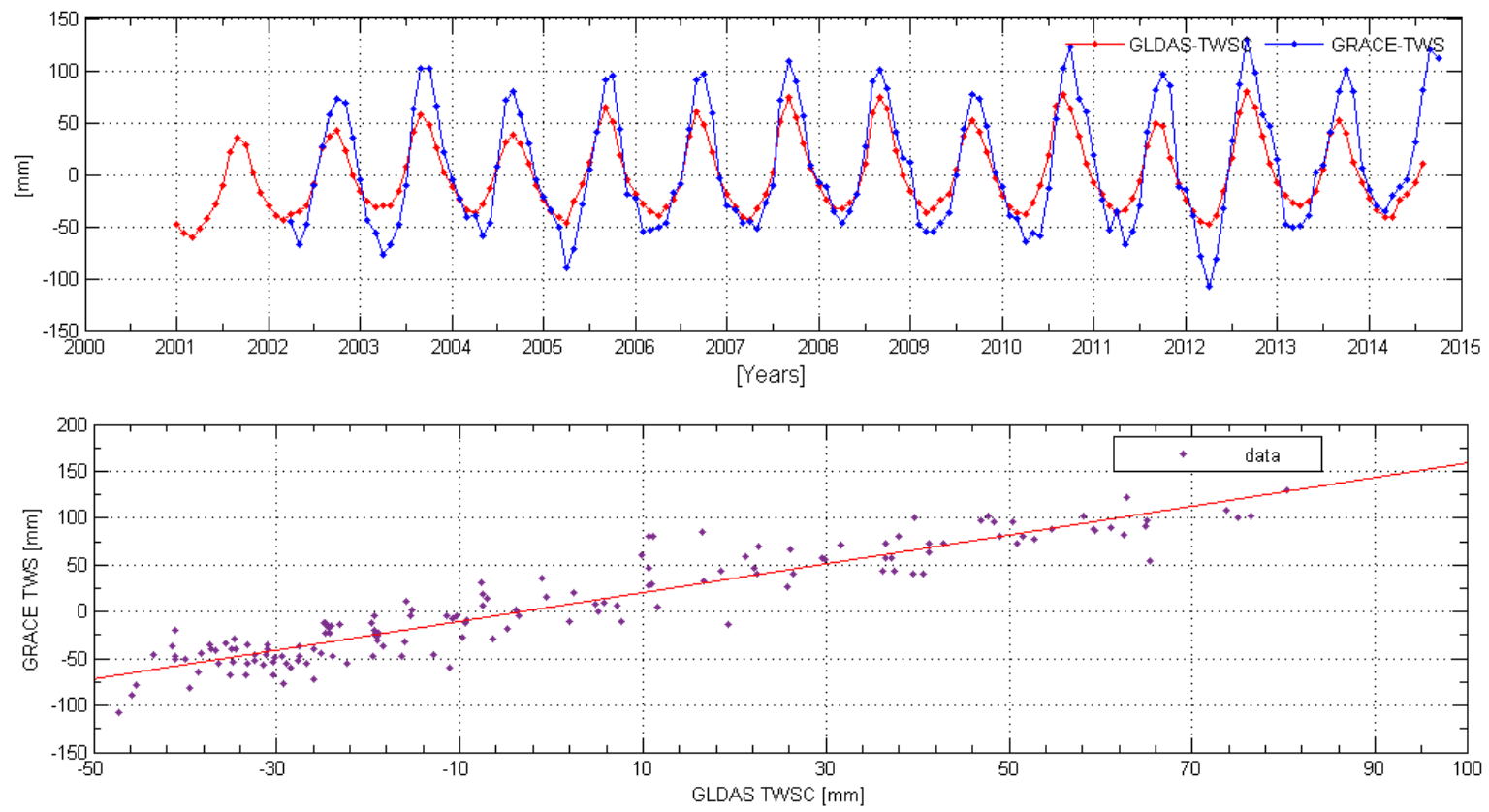

Figure 17: Comparison between GRACE-derived TWS and GLDAS-derived terrestrial water storage content (TWSC). Top: Time series of GRACE-derived TWS (2002-2014) and GLDAS-TWSC for the period during 2001-2014 averaged over the Lake Chad basin. Bottom: Regression fit on GRACE TWS and GLDAS TWSC over Lake Chad basin for the common time period (i.e., 2002-2014). 
1009

1010

1011

1012

1013

1014

1015

1016

1017

\section{Acknowledgments}

Christopher E. Ndehedehe and Nathan O. Agutu are grateful to Curtin University for the Curtin Strategic International Research Scholarship (CSIRS) programme. We thank the Editor and Journal of Hydrology's anonymous reviewers for their useful comments, which helped improved the manuscript. The authors are grateful to Center for Space Research, United States Department of Agriculture, National Oceanic and Atmospheric Administration, and National Aeronautics and Space Administration for all the data used in this study. The support and contributions of Tertiary Trust Fund (TETFUND) Nigeria towards this research is also gratefully acknowledged. 


\section{References}

Adler, R. F., Huffman, G. J., Chang, A., Ferraro, R., Xie, P.-P., Janowiak, J., Rudolf, B., Schneider, U., Curtis, S., Bolvin, D., Gruber, A., Susskind, J., Arkin, P., and Nelkin, E. (2003). The version-2 Global Precipitation Climatology Project (GPCP) monthly precipitation analysis (1979Present). Journal of Hydrometeorology, 4(6):1147-1167. doi:10.1175/1525-7541(2003)004¡1147:TVGPCP ¿2.0.CO;2.

AghaKouchak, A. (2015). A multivariate approach for persistence-based drought prediction: Application to the 2010-2011 East Africa drought. Journal of Hydrology, 526:127 - 135. doi:10.1016/j.jhydrol.2014.09.063.

Aires, F., Rossow, W. B., and ChéDin, A. (2002). Rotation of EOFs by the independent component analysis: Toward a solution of the mixing problem in the decomposition of geophysical time series. Journal of the Atmospheric Sciences, 59:111-123. doi:10.1175/15200469(2002)059;0111:ROEBTI ¿2.0.CO;2.

Alfa, N. I., Adeofun, C. O., and Ologunorisa, E. T. (2008). Assessment of changes in aerial extent of Lake Chad using satellite remote sensing data. Journal of Applied Sciences and Environmental Mangement, 12(1):101-107.

Ali, A. and Lebel, T. (2009). The Sahelian standardized rainfall index revisited. International Journal Of Climatology, 29:1705-1714. doi:10.1002/joc.1832.

Bader, J. and Latif, M. (2011). The 1983 drought in the West Sahel: A case study. Climate Dynamics, 36(3-4):463-472. doi:10.1007/s00382-009-0700-y.

Ball, G. H. and Hall, D. J. (1965). Isodata, a novel method of data analysis and pattern classification. Technical Report, Menlo Park, California: Stanford Research Intitute. Retrieved from:http://oai.dtic.mil/oai/oai?verb=getRecord\&metadataPrefix=html\&identifier=AD069 9616 Accessed 25 March, 2016.

Baup, F., Frappart, F., and Maubant, J. (2014). Combining high-resolution satellite images and altimetry to estimate the volume of small lakes. Hydrology and Earth System Sciences, 18(5):2007-2020. doi:10.5194/hess-18-2007-2014.

Baur, O., Kuhn, M., and Featherstone, W. E. (2009). GRACE-derived ice-mass variations over Greenland by accounting for leakage effects. Journal of Geophysical Research: Solid Earth, 114(B6):B06407. doi:10.1029/2008JB006239. 
Bazrafshan, J., Hejabi, S., and Rahimi, J. (2014). Drought monitoring using the multivariate standardized precipitation index (MSPI). Water Resources Mangagement, 28:1045-1060. doi:10.1007/s11269-014-0533-2.

Bekoe, E. O. and Logah, F. Y. (2013). The impact of droughts and climate change on electricity generation in Ghana. Environmental Sciences, 1(1):13-24.

Belda, S., García-García, D., and Ferrándiz, J. M. (2015). On the decorrelation filtering of RL05 GRACE data for global applications. Geophysical Journal International, 200:173-184. doi:10.1093/gji/ggu386.

Birkett, C. M. (2000). Synergistic remote sensing of Lake Chad:Variability of basin inundation. Remote Sensing of Environment, 72(218236).

Boergens, E., Rangelova, E., Sideris, M. G., and Kusche, J. (2014). Assessment of the capabilities of the temporal and spatiotemporal ICA method for geophysical signal separation in GRACE data. Journal of Geophysical Research Solid Earth, 119:4429-4447,. doi:10.1002/2013JB010452.

Bonaccorso, B., Bordi, I., Cancelliere, A., Rossi, G., and Sutera, A. (2003). Spatial variability of drought: An analysis of the SPI in Sicily. Water Resources Management, 17(4):273-296. doi:10.1023/A:1024716530289.

Cardoso, J.-F. (1991). Super-symmetric decomposition of the fourth-order cumulant tensor, blind identification of more sources than sensors. Retrieved from:http://perso.telecomparistech.fr/ cardoso/Papers.PDF/icassp91.pdf. Accessed 15 January 2016.

Cardoso, J. F. (1999). High-Order contrasts for Independent Component Analysis. Neural Computation, 11:157-192.

Cardoso, J. F. and Souloumiac, A. (1993). Blind beamforming for non-gaussian signals. IEE Proceedings, 140(6):362-370.

Cheng, M. K., Tapley, B. D., and Ries, J. C. (2013). Deceleration in the Earth's oblateness. Journal of Geophysical Research, 118:1-8. doi:10.1002/jgrb.50058.

Coe, M. T. and Birkett, C. M. (2004). Calculation of river discharge and prediction of lake height from satellite radar altimetry: Example for the Lake Chad basin. Water Resources Research, 40(10):W10205. doi:10.1029/2003WR002543. 
Coe, M. T. and Foley, J. A. (2001). Human and natural impacts on the water resources of the Lake Chad basin. Journal Of Geophysical Research, 106(4):3349-3356. doi:01480227/01/2000JD900587509.00.

Common, P. (1994). Independent component analysis, A new concept? Signal Processing, $36: 287-314$.

Descroix, L., Mahé, G., Lebel, T., Favreau, G., Galle, S., Gautier, E., Olivry, J.-C., Albergel, J., Amogu, O., Cappelaere, B., Dessouassi, R., Diedhiou, A., Breton, E. L., Mamadou, I., and Sighomnou, D. (2009). Spatio-temporal variability of hydrological regimes around the boundaries between Sahelian and Sudanian areas of West Africa: A synthesis. Journal of Hydrology, 375(12):90-102. doi:10.1016/j.jhydrol.2008.12.012.

Diatta, S. and Fink, A. H. (2014). Statistical relationship between remote climate indices and West African monsoon variability. International Journal of Climatology, 34(12):3348-3367. doi:0.1002/joc.3912.

Dirmeyer, P. A., Guo, Z., and Gao, X. (2004). Comparison, validation, and transferability of eight multiyear global soil wetness products. Journal of Hydrometeorolgy, 5:1011-1033. doi:10.1175/JHM-388.1.

Duan, Z. and Bastiaanssen, W. (2013a). Estimating water volume variations in lakes and reservoirs from four operational satellite altimetry databases and satellite imagery data. Remote Sensing of Environment, 134:403 - 416. doi:10.1016/j.rse.2013.03.010.

Duan, Z. and Bastiaanssen, W. G. M. (2013b). First results from Version 7 TRMM 3B43 precipitation product in combination with a new downscaling calibration procedure. Remote Sensing of Environment, 131(0):1-13. doi: 10.1016/j.rse.2012.12.002 131(0),1-13.

Fan, Y. and Dool, H. V. (2004). Climate prediction center global monthly soil moisture data set at $0.5^{\circ}$ resolution for 1948 to present. Journal Of Geophysical Research, 109:D10102. doi:10.1029/2003JD004345.

FAO (1997). Irrigation potential in Africa: a basin approach. FAO Land and Water Bulletin, 4. Retrieved from:https://books.google.com.au/books. Accessed 28 September, 2015.

Farahmand, A. and AghaKouchak, A. (2015). A generalized framework for deriving nonparametric standardized drought indicators. Advances in Water Resources, (76):140-145. doi:/10.1016/j.advwatres.2014.11.012. 
Forootan, E. and Kusche, J. (2012). Separation of global time-variable gravity signals into maximally independent components. Journal of Geodesy, 86(7):477-497. doi:10.1007/s00190011-0532-5.

Frappart, F., Ramillien, G., Leblanc, M., Tweed, S. O., Bonnet, M.-P., and Maisongrande, P. (2011). An independent component analysis filtering approach for estimating continental hydrology in the GRACE gravity data. Remote Sensing of Environment, 115(1):187 - 204. doi:doi.org/10.1016/j.rse.2010.08.017.

Frappart, F., Ramillien, G., Maisongrande, P., and Bonnet, M.-P. (2010). Denoising satellite gravity signals by independent component analysis. Geoscience and Remote Sensing Letters, IEEE, 7(3):421-425. doi:10.1109/LGRS.2009.2037837.

Gbuyiro, S. O., Ojo, O., Iso, M., Okoloye, C., and Idowu, O. (2001). Climate and water resources management. WEDC conference Zambia, 27:383-386. Retrieved from: www.wedc.lboro.ac.uk/resources/conference/27/Gbuyiro.pdf. Accessed 15 May 2015.

Giannini, A., Salack, S., Lodoun, T., Ali, A., Gaye, A., and Ndiaye, O. (2013). A unifying view of climate change in the Sahel linking intra-seasonal, interannual and longer time scales. Environmental Research Letters, 8:1-8. doi:10.1088/1748-9326/8/2/024010.

Giannini, A., Saravanan, R., and Chang, P. (2003). Oceanic forcingof Sahel rainfall on interannual to decadal time scales. Science, 302(5647):1027-1030. doi:10.1126/science.1089357.

Gosset, M., Viarre, J., Quantin, G., and Alcoba, M. (2013). Evaluation of several rainfall products used for hydrological applications over West Africa using two high-resolution gauge networks. Quarterly Journal of the Royal Meteorological Society, 139:923-940. doi:10.1002/qj.2130.

Greve, P., Orlowsky, B., Mueller, B., Sheffield, J., Reichstein, M., and Seneviratne, S. L. (2014). Global assessment of trends in wetting and drying over land. Nature Geoscience, 7:716-721. doi:10.1038/NGE02247.

Grippa, M., Kergoat, L., Frappart, F., Araud, Q., Boone, A., de Rosnay, P., Lemoine, J. M., Gascoin, S., Balsamo, G., Ottl, C., Decharme, B., Saux-Picart, S., and Ramillien, G. (2011). Land water storage variability over West Africa estimated by Gravity Recovery and Climate Experiment (GRACE) and land surface models. Water Resources Research, 47(5):W05549. doi:10.1029/2009wr008856. 
Hao, Z. and AghaKouchak, A. (2013). Multivariate standardized drought index: A parametric multi-index model. Advances in Water Resources, (57):12-18. doi:10.1016/j.advwatres.2013.03.009.

Hao, Z. and AghaKouchak, A. (2014). A nonparametric multivariate multi-index drought monitoring framework. Journal of Hydrometeorology, 15(1):89-101. doi:10.1175/JHM-D12-0160.1.

Hayes, M. J., Svoboda, M. D., Wilhite, D. A., and Vanyarkho, O. V. (1999). Monitoring the 1996 drought using the standardized precipitation index. Bulletin of the American Meteorological Society, 80:429-438. doi:10.1175/1520-0477(1999)080;0429:MTDUTS ¿2.0.CO;2.

Hinderer, J., de Linage, C., Boya, J.-P., Gegout, P., Masson, F., Rogister, Y., Amalvict, M., Pfeffer, J., Littel, F., Luck, B., Bayerb, R., Champollion, C., Collard, P., Moigne, N. L., Diamentc, M., Deroussi, S., de Viron, O., Biancale, R., Lemoine, J.-M., Bonvalot, S., Gabalda, G., Bock, O., Genthon, P., Boucher, M., Favreau, G., Sguis, L., Delclaux, F., Cappelaere, B., Oi, M., Descloitresh, M., Galleh, S., Laurent, J.-P., Legchenko, A., and Bouink, M.-N. (2009). The GHYRAF (Gravity and Hydrology in Africa) experiment: Description and first results. Journal of Geodynamics, 48:172-181. doi:10.1016/j.jog.2009.09.014.

Huang, S., Huang, Q., Chang, J., Zhu, Y., Leng, G., and Xing, L. (2015). Drought structure based on a nonparametric multivariate standardized drought index across the Yellow River basin, China . Journal of Hydrology, 530:127 - 136. doi:10.1016/j.jhydrol.2015.09.042.

Huffman, G. J., Adler, R. F., Bolvin, D. T., and Gu, G. (2009). Improving the global precipitation record: GPCP Version 2.1. Geophysical Research Letters, 36(17):L17808. doi:10.1029/2009GL040000.

Huffman, G. J., Adler, R. F., Bolvin, D. T., Gu, G., Nelkin, E. J., Bowman, K. P., Hong, Y., Stocker, E. F., and Wolff, D. B. (2007). The TRMM Multisatellite Precipitation Analysis (TMPA): Quasi-Global, Multiyear, Combined-Sensor Precipitation Estimates at Fine Scales. Journal Of Hydrometeorology, 8:38-55. doi:10.1175/JHM560.1.

Inogwabini, B.-I., Sandokan, B. M., and Ndunda, M. (2006). A dramatic decline in rainfall regime in the Congo Basin: evidence from a thirty four-year data set from the Mabali scientific research centre, Democratic Republic Of Congo. The International Journal Of Meteorology, 31(312):278-285. 
Jolliffe, I. T. (2002). Principal component analysis (second edition). Springer Series in Statistics. Springer, New York.

Komuscu, A. U. (1999). Using the SPI to analyze spatial and temporal patterns of drought in Turkey. Drought Network News, 11(1):7-13.

Kummerow, C., Simpson, J., Thiele, O., Barnes, W., Chang, A. T. C., Stocker, E., Adler, R. F., Hou, A., Kakar, R., Wentz, F., Ashcroft, P., Kozu, T., Hong, Y., Okamoto, K., Iguchi, T., Kuroiwa, H., Im, E., Haddad, Z., Huffman, G., Ferrier, B., Olson, W. S., Zipser, E., Smith, E. A., Wilheit, T. T., North, G., Krishnamurti, T., and Nakamura, K. (2000). The status of the Tropical Rainfall Measuring Mission (TRMM) after two years in orbit. Journal of Applied Meteorology, 39(12):1965-1982. doi:10.1175/1520-0450(2001)040;1965:TSOTTR ¿2.0.CO;2.

Kusche, J. (2007). Approximate decorrelation and non-isotropic smoothing of time-variable GRACE-type gravity field models. Journal of Geodesy, 81(11):733-749. doi:10.1007/s00190007-0143-3.

Landerer, F. W. and Swenson, S. C. (2012). Accuracy of scaled GRACE terrestrial water storage estimates. Water Resources Research, 48(4):W04531. doi:10.1029/2011WR011453.

Lebel, T. and Ali, A. (2009). A physical basis for the interannual variability of rainfall in the Sahel. Quarterly Journal Of The Royal Meteorological Society, 375(1-2):5264. doi:10.1016/j.jhydrol.2008.11.030.

Lebel, T., Cappelaere, B., Galle, S., Hanan, N., Kergoat, L., Levis, S., Vieux, B., Descroix, L., Gosset, M., Mougin, E., Peugeot, C., and Seguis, L. (2009). AMMA-CATCH studies in the Sahelian region of West-Africa: An overview . Journal of Hydrology, 375(12):3 - 13.

Leblanc, M., Leduc, C., Razack, M., Lemoalle, J., Dagorne, D., and Mofor, L. (2003). Applications of remote sensing and GIS for groundwater modelling of large semiarid areas: example of the Lake Chad Basin, Africa. Hydrology of the Mediterranean and Semiarid Regions, (278):186-191. proceedings of the international symposium held at Montpellier, April 2003.

Lemoalle, J., Bader, J.-C., Leblanc, M., and Sedick, A. (2012). Recent changes in Lake Chad: Observations, simulations and management options (19732011). Global and Planetary Change, 8081:247 - 254. doi:10.1016/j.gloplacha.2011.07.004.

Li, B. and Rodell, M. (2015). Evaluation of a model-based groundwater drought indicator in the conterminous U.S. . Journal of Hydrology, 526:78 - 88. doi:10.1016/j.jhydrol.2014.09.027. 
Lloyd-Hughes, B. (2012). A spatio-temporal structure-based approach to drought characterisation. International Journal of Climatology, 32(3):406-418. doi:10.1002/joc.2280.

Long, D., Longuevergne, L., and Scanlon, B. R. (2015). Global analysis of approaches for deriving total water storage changes from GRACE satellites. Water Resources Research, 51(4):2574-2594. doi:10.1002/2014WR016853.

Loon, A. F. V. (2015). Hydrological drought explained. WIREs Water, 2:359-392. doi:10.1002/wat2.1085.

Lopez, T., Antoine, R., Kerr, Y., Darrozes, J., Rabinowicz, M., Ramillien, G., Cazenave, A., and Genthon, P. (2016). Subsurface hydrology of the Lake Chad Basin from convection modelling and observations. Surveys in Geophysics, 37(2):471-502. doi:10.1007/s10712-0169363-5.

Masih, I., Maskey, S., Mussá, F. E. F., and Trambauer, P. (2014). A review of droughts on the African continent: a geospatial and long-term perspective. Hydrology and Earth System Sciences, 18(9):3635-3649. doi:10.5194/hess-18-3635-2014.

McKee, T. B., Doeskin, N. J., and Kieist, J. (1993). The relationship of drought frequency and duration to time scales. Conference on Applied Climatology, American Meteorological Society,Boston, Massachusetts, pages 179-184. Retrieved from:www.ccc.atmos.colostate.edu/relationshipofdroughtfrequency.pdf. Accessed 27 June, 2014 .

Mohino, E., Rodrguez-Fonseca, B., Losada, T., Gervois, S., Janicot, S., Bader, J., Ruti, P., and Chauvin, F. (2011). Changes in the interannual SST-forced signals on West African rainfall. AGCM intercomparison. Climate Dynamics, 37(9-10):1707-1725. doi:10.1007/s00382-0111093-2.

Moore, P. and Williams, S. D. P. (2014). Integration of altimetry lake lavels and GRACE gravimetry over Africa: Inferences for terrestrial water storage change 2003-2011. Water Resources Research, 50:9696-9720. doi:10.1002/2014WR015506.

Ndehedehe, C., Awange, J., Agutu, N., Kuhn, M., and Heck, B. (2016a). Understanding changes in terrestrial water storage over West Africa between 2002 and 2014. Advances in Water Resources, 88:211-230. doi:10.1016/j.advwatres.2015.12.009. 
Ndehedehe, C. E., Awange, J. L., Corner, R., Kuhn, M., and Okwuashi, O. (2016b). On the potentials of multiple climate variables in assessing the spatio-temporal characteristics of hydrological droughts over the Volta Basin. Science of the Total Environment, 557-558:819837. doi:10.1016/j.scitotenv.2016.03.004.

Nicholson, S. (2013). The West African Sahel: a review of recent studies on the rainfall regime and its interannual variability. ISRN Meteorology, 2013(453521):1-32. doi:10.1155/2013/453521.

Nicholson, S. E., Some, B., and Kone, B. (2000). An Analysis of Recent Rainfall Conditions in West Africa, Including the Rainy Seasons of the $1997 \mathrm{El} \mathrm{Nin̈o}$ and the 1998 La Nia Years. Journal of Climate, 13(14):2628-2640. doi:10.1175/15200442(2000)013¡2628:AAORRC¿2.0.CO;2.

Odada, E. O., Oyebande, L., and Oguntola, J. A. (2005). Lake Chad. Experience and Lessons Learned Briefed, pages 75-91. Retrieved from:www.worldlakes.org/uploads/06-Lake-Chad27February2006.pdf. Accessed 5 October, 2015.

Okonkwo, C., Demoz, B., and Gebremariam, S. (2014). Characteristics of Lake Chad level variability and links to ENSO, precipitate, and river discharge. The Scientifc World Journal, 13(4):13. doi:10.1155/2014/145893.

Okonkwo, C., Demoz, B., and Onyeukwu, K. (2013). Characteristics of drought indices and rainfall in Lake Chad Basin. International Journal Of Remote Sensing, 34(22):7945-7961. doi:10.1080/01431161.2013.827813.

Paeth, H., Fink, A., Pohle, S., Keis, F., Machel, H., and Samimi, C. (2012). Meteorological characteristics and potential causes of the 2007 flood in sub-Saharan Africa. International Journal of Climatology, 31:1908-1926. doi:10.1002/Joc.2199.

Reager, J. T., Thomas, B. F., and Famiglietti, J. S. (2014). River basin flood potential inferred using GRACE gravity observations at several months lead time. Nature Geoscience, 7(8):588-592. doi:10.1038/ngeo2203.

Reynolds, R. W., Rayne, N. A., Smith, T. M., Stokes, D. C., and Wang, W. (2002). An improved in situ and satellite SST analysis for climate. Journal of Climate, 15(3):16091625. doi:10.1175/1520-0442(2002)0153C1609:AIISAS3E2.0.CO;2. 
Rodell, M., Houser, P. R., Jambor, U., Gottschalck, J., Mitchell, K., Meng, K., Arsenault, C. J., Cosgrove, B., Radakovich, J., Bosilovich, M., Entin, J. K., Walker, J. P., Lohmann, D., and Toll, D. (2004). The global land data assimilation system. Bulletin of American Meteorological Society, 85(3):381-394. doi:10.1175/BAMS-85-3-381.R.

Rodrguez-Fonseca, B., Janicot, S., Mohino, E., Losada, T., Bader, J., Caminade, C., Chauvin, F., Fontaine, B., Garca-Serrano, J., Gervois, S., Joly, M., Polo, I., Ruti, P., Roucou, P., and Voldoire, A. (2011). Interannual and decadal SST-forced responses of the West African monsoon. Atmospheric Science Letters, 12:67-74. doi:10.1002/asl.308.

Rouault, M. and Richard, Y. (2003). Intensity and spatial extension of drought in South Africa at different time scales. Water SA, 29(4):489-500.

Santos, J. a. F., Pulido-Calvo, I., and Portela, M. M. (2010). Spatial and temporal variability of droughts in Portugal. Water Resources Research, 46(3):W03503. doi:10.1029/2009WR008071.

Schewe, J., Heinke, J., Gerten, D., Haddeland, I., Arnell, N. W., Clark, D. B., Dankers, R., Eisner, S., Fekete, B. M., Colón-Gonzlez, F. J., Gosling, S. N., Kim, H., Liu, X., Masaki, Y., Portmann, F. T., Satoh, Y., Stacke, T., Tang, Q., Wada, Y., Wisser, D., Albrecht, T., Frieler, K., Piontek, F., Warszawski, L., and Kabat, P. (2013). Multimodel assessment of water scarcity under climate change. PNAS, 111(9):3245-3250,. doi:10.1073/pnas.1222460110.

Shukla, S. and Wood, A. W. (2008). Use of a standardized runoff index for characterizing hydrologic drought. Geophysical Research Letters, 35(2):L02405. 10.1029/2007GL032487.

Svoboda, M., Hayes, M., and Wood, D. (2012). Standardized precipitation index user guide. World Meteorological Organization, WMO-No 1090, Geneva. Retrieved from:http://www.wamis.org/agm/pubs/SPI/WMO-1090-EN.pdf Accessed 13 April, 2016.

Swenson, S., Chambers, D., and Wahr, J. (2008). Estimating geocenter variations from a combination of GRACE and ocean model output. Geophysical Research Letters, 31:1-4. doi:10.1029/ 2004GL019920.

Swenson, S. and Wahr, J. (2002). Methods for inferring regional surface-mass anomalies from Gravity Recovery and Climate Experiment (GRACE) measurements of time-variable gravity. Journal of Geophysical Research-Solid Earth, 107(B9). doi:10.1029/2001jb000576. 
Tapley, B., Bettadpur, S., Watkins, M., and Reigber, C. (2004). The Gravity Recovery and Climate Experiment: Mission overview and early results. Geophysical Research Letters, 31:1-4. doi:10.1029/ 2004GL019920.

Theis, F. J., Gruber, P., Keck, I. R., Meyer-bse, A., and Lang, E. W. (2005). Spatiotemporal blind source separation using double-sided approximate joint diagonalization. In In Proc. EUSIPCO 2005.

Tourian, M., Elmi, O., Chen, Q., Devaraju, B., Roohi, S., and Sneeuw, N. (2015). A spaceborne multisensor approach to monitor the desiccation of Lake Urmia in Iran . Remote Sensing of Environment, 156:349 - 360. doi:10.1016/j.rse.2014.10.006.

Vassolo, S. (2012). Groundwater need assessment Lake Chad Basin. Institute for Geosciences and Natural Resources. Retrieved from:http://splashera.net/downloads/groundwater $/ 9_{L} C B C_{f}$ inal $_{r}$ eport.pdf. Accessed 03 November, 2015.

Vicente-Serrano, S. M. (2006). Spatial and temporal analysis of droughts in the Iberian Peninsula (19102000). Hydrological Sciences Journal, 51(1):83-97. doi:10.1623/hysj.51.1.83.

Wahr, J., Molenaar, M., and Bryan, F. (1998). Time variability of the Earth's gravity field: Hydrological and oceanic effects and their possible detection using GRACE. Journal of Geophysical Research-Solid Earth, 103(B12):30205-30229. doi:10.1029/98jb02844.

Wald, L. (1990). Monitoring the decrease of Lake Chad from space. Geocarto International, 5(3):31-36. doi: 10.1080/10106049009354266.

Werth, S., Gntner, A., Schmidt, R., and Kusche, J. (2009). Evaluation of GRACE filter tools from a hydrological perspective. Geophysical Journal International, 179(3):1499-1515.

Wouters, B., Bonin, J. A., Chambers, D. P., Riva, R. E. M., Sasgen, I., and Wahr, J. (2014). GRACE, time-varying gravity, Earth system dynamics and climate change. Reports on Progress in Physics, 77(11):116801. doi:10.1088/0034-4885/77/11/116801.

Wouters, B. and Schrama, E. J. O. (2007). Improved accuracy of GRACE gravity solutions through empirical orthogonal function filtering of spherical harmonics. Geophysical Research Letters, 34(23):L23711. doi:10.1029/2007GL032098. 
1311

1312

1313

1316

1317

1318

Yirdaw, S. Z., Snelgrove, K., and Agboma, C. (2008). GRACE satellite observations of terrestrial moisture changes for drought characterization in the Canadian Prairie. Journal of Hydrology, 356:84-92.

Ziehe, A. (2005). Blind source separation based on joint diagonalization of matrices with applications in biomedical signal processing. PhD thesis, Universitat Potsdam. Retrieved from:http://en.youscribe.com/catalogue/reports-and-theses/knowledge/blindsource-separation-based-on-joint-diagonalization-of-matrices-1424347. Accessed 15 May 2015. 